\title{
ISLAS EN LA LAGUNA DEL SISTEMA. LA RELACIÓN DE KANT CON FICHTE Y SCHELLING EN EL OPUS POSTUMUM
}

\author{
Félix DUQUE \\ Universidad Autónoma de Madrid
}

RESUMEN: Invirtiendo la imagen kantiana de la isla segura del entendimiento en medio del mar embravecido de la sensibilidad y la fantasia, sería conveniente insinuar que, al menos en su fragmentaria etapa final - en el llamado Opus postumum-, el sistema de Kant se asemeja más bien a una laguna -con sus olas y remolinos, sin embargo - tachonada de islas (las diferentes funciones de la razón, la dificil convivencia de las dos partes metafisicas con la filosofia trascendental, a través de frágiles transiciones, etc.). De abt los intentos de los llamados «amigos hipercríticos» (Reinhold, Beck, Fichte) por reunir esos membra disjecta en un sistema bien trabado, a partir de un "punto de vista" supremo desde el que echar puentes sólidos entre las islas. Particular importancia teórica reviste al respecto la comparación del anciano maestro con sus dos mejores $\longrightarrow y$ más discolos- discípulos indirectos: Fichte y Schelling (comparación, según la "cosa misma del pensar», ya que no leyó nada de ellos). Puntos fundamentales de fricción y cercanía serán el estatuto de la "cosa en st", el problema de la Idea asintótica ("Dios" como autoproducción de la Razón, en el último Kant; "Yo" en Fichte, aun cuando posiblemente ambos términos se copertenezcan) y el de la autoafección y autoconciencia. Cabe sospechar un constructivismo en el último Kant, alejado de las posiciones idealistas, aunque su defensa de un "resto" irreductible permite sospechar una cercania profunda con el factum de la existencia, propio de Schelling ya a partir de su Panorama (Allgemeine Übersicht).

El 23 de junio de 1796 impartió el Sr. Profesor Kant su última lección en la Universidad de Königsberg. Y aunque, como es sabido, no dejara de publicar desde entonces obras de cierta envergadura, lo cierto es que por esas fechas (o poco antes, si atendemos a algunos Lose Blätter del Konvolut $I V$ del Opus postumum) se retirará casi por completo del mundanal ruido para acometer una empresa que en privado habría prometido "desde hace unos años" el pro- 
pio Kant, y que, como le recuenda el fiel Kiesewetter, thabría de oratur de: wa

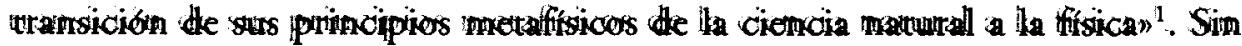

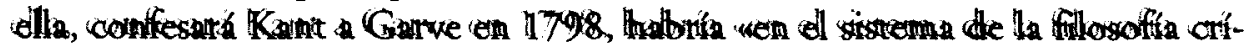

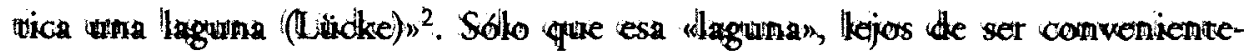
mente cerradt, se irh emsandhwindo con el riempo hasta comwervirse en win mar tempestuoso que menazara con destruir inchuso la tientra finme de la Analíica trascendental de lla primera Critica. Ya en la cirada carta a Garve callifica Kamt su proyractada wobra de usuplicio de Trintalon. El símil mo prodín ser más ade-

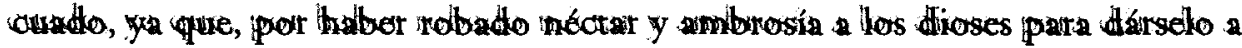
sur amigos, Trantalo había sido castigado a penmanacer sumergido hasta el cueTho precisamente en wha laguna, oon antboles cargados de fruta a su alcance, pero cutyas ramas oran elevadas repentrinamemite por el viento siempre que el infeliz incentaba alcanzar una fruta.

Sabomos muty bien en quá consistín ese udimenno de los dioses" que Kann-

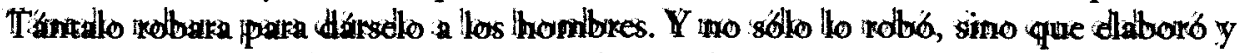

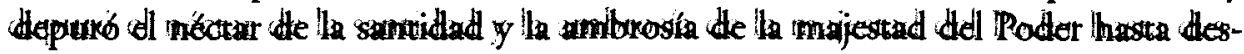

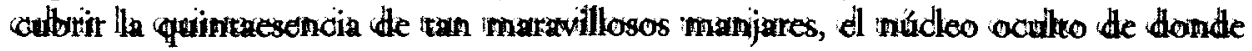
dllos womabun su fuerza. Su hermoso nontbre es razón, y no desde luego sólo indi-

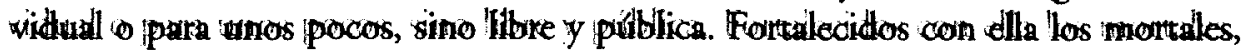
los dioses del didlo y sur repiresentantes en lla tienra se verán despojados para siempre de surs prinitlegios ancestralles. Cosi al imicio dtel Prólogo a la primera edición de Iha Orfuica dice en effacto Kant: wNuestra era es lla cera propia de lla critica, a la cual wodo debe someterse. La religión por su samidad y la legislación por su majestad protenthen por llo comín surstraerse a dlla. Pero antonces suscitan una justificadta sospedha en su comtra y mo pureden exigir sincero respeto, conferido por la razón

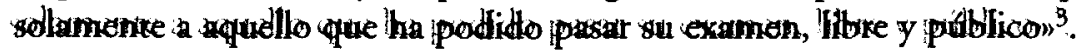

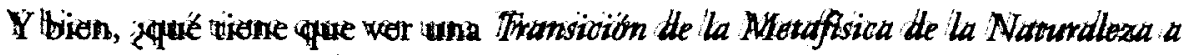

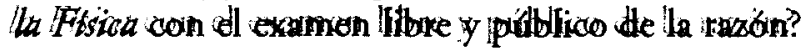

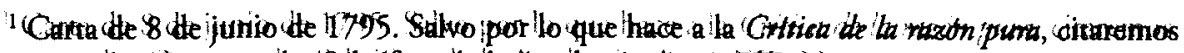

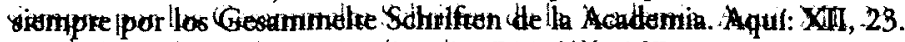

${ }^{2}$ Conth de 21 de septiambre de 17988 . XIII, 257.

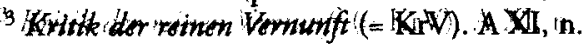


Para scercarmos a cste punto, basta con que companemos th desconfianna y hassa hostillidad con que los cientuificos de la tpoca acogienon los Metaphysische Anffengyoünde lkanniamos de 1786 (obra de la que se sigue casi de umodo mocesario la cmpresa del Übergeng) con d cmiansiasmo que csa obra

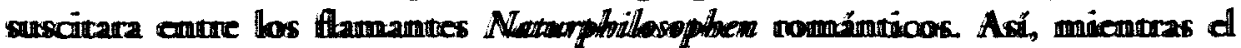

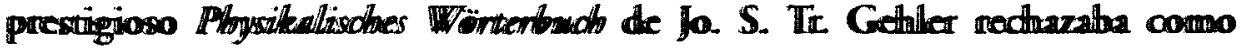

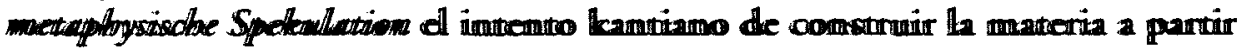
de dos furerzas onigimarias', Schelling saluadaba la obra como liberación de uma

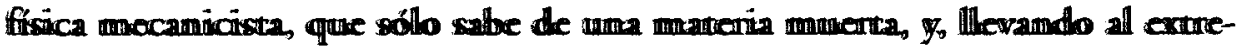

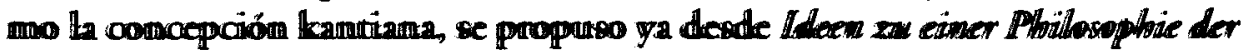

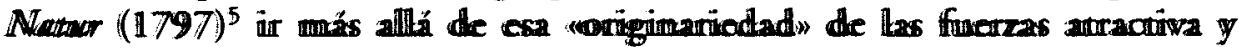

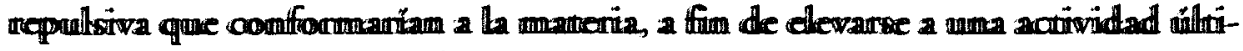

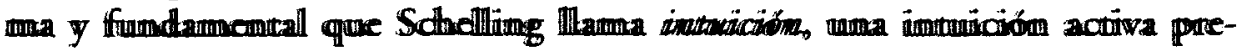

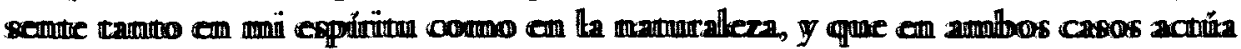
por lithertad (AA 210 s.). Y Framz wom Bavder Illegarí a decir qume Kamr: (2ami-

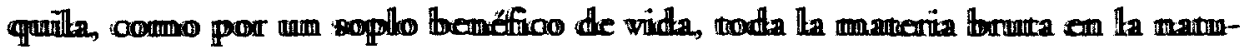
rallers, de modo que en costa mo thay ya simo meatrenia virza, presemite por

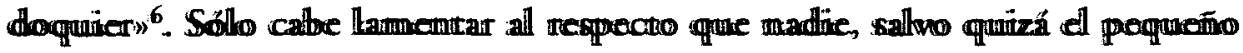

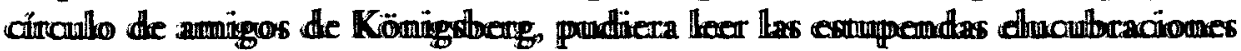

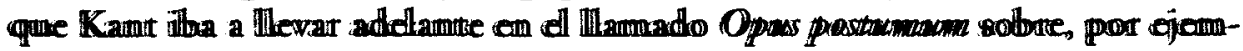

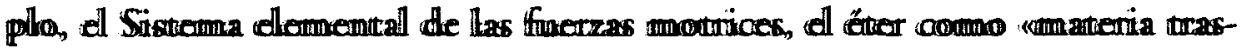

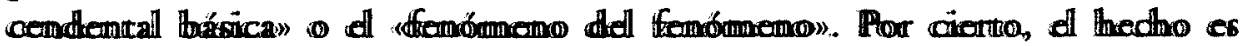

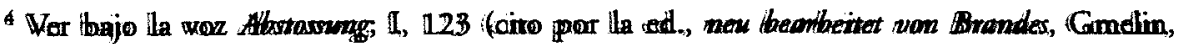
Houner, Mundke, Pfaff. de Laipzig 1825, neu erc)). Más cońtica aún es la (oppinión soibre el influ-

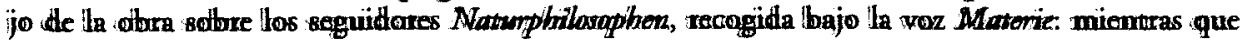
éros, para no rqperiir las pallabras del macstro, habrían usado palabras dándales un significado arthitrario, con lo que se hadbrian entregado a algo que upara rodos era el más absurdo de los sis-

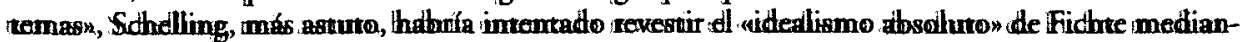

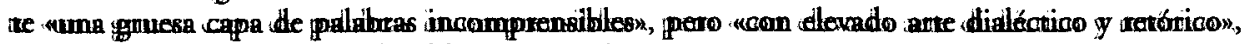
de unanera que gran parte del público aceptó del conjumro como un sistoma wigurosamemte cienti-

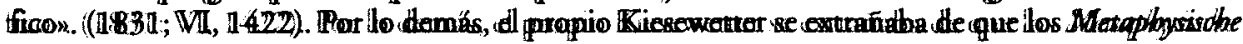

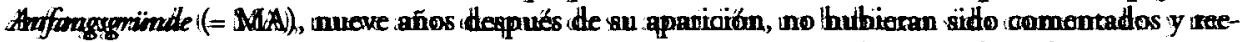

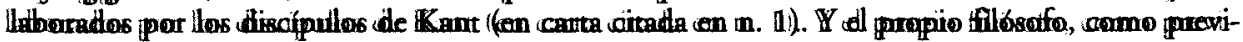

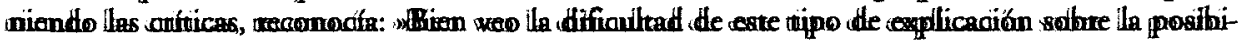

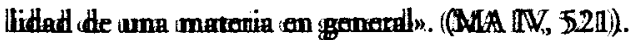

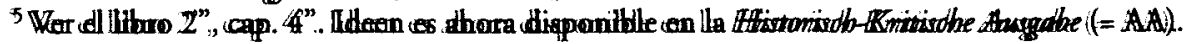

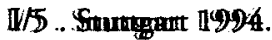

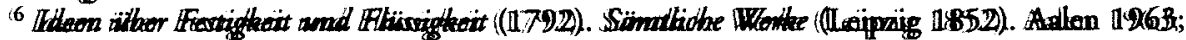
$\mathbb{1} / 3 \mathbf{3} 185, \mathrm{n}$. 
lamentable también desde el punto de vista estrictamente científico: pues es posible que gran parte de los desvaríos ulteriores de los Naturphilosophen se hubieran evitado de conocer la obra póstuma.

Sea como fuere, lo importante es señalar que la empresa kantiana sigue, como no podía ser menos, un doble programa. Por un lado, ciertamente, se propone una fundamentación trascendental de la ciencia de la naturaleza, con estricta atención a las teorías empíricas que Kant podía conocer. Pero por otro, y ello es lo relevante para mí, se proponía, rebajando las ínfulas de una consideración de la física puramente matemática y mecánica, à la Newton, encontrar el eslabón que pudiera enlazar la Metafísica de la Naturaleza (y, por ende, la Filosofía Trascendental) con la Física como un sistema de lo empírico (y no como un mero agregado de fenómenos, enlazados sólo formalmente por las matemáticas), de la misma manera que la Metafísica de las Costumbres había de poder justificar la aplicación de los principios puros del deber a los casos de experiencia ${ }^{7}$. Sólo así se lograría presentar la entera experiencia como un sistema omnicomprehensivo. Con ello se habría logrado, yendo más allá de las "Anticipaciones de la percepción" de la primera Crítica, una anticipación quoad materiale, aunque sólo problemática (sensu kantiano) de la experiencia, pero entendiendo a ésta desde luego como unidad total colectiva, y por ende sólo como una totalidad (Ganzheit) cogitabile, en favor de lo empírico, o sea como justificación y ordenación previa de una Allheit u omnitud distributiva (dabile), que sólo asintóticamente se iría aproximando a la experiencia como determinación omnímoda. De este modo, la Transición serviría de hilo conductor para la aproximación in indefinitum del sistema natural, propio de una natura materialiter spectata (el conjunto de los fenómenos), al sistema doctrinal, propio de una natura formaliter spectata (conjunto de leyes universales deducibles de los pre-

${ }^{7}$ Tugendlehre. Metaphysik der Sitten. VI, 468. Es curioso que Kant hable aquí (1798) como si él hubiera ya cumplido la tarea del Übergang y el público lo supiera. Comienza en efecto diciendo: «Además, al igual que se requiere pasar de la Metafisica de la Naturaleza a la Física, un paso (Überschritt) que tiene sus reglas particulares, así también se propone la Metafísica de las Costumbres, con razón, hacer algo análogo." A la vista de los fragmentos, bien podemos afirmar que Kant pensaba por esta fecha concluir en breve plazo su obra (véase la "Correspondencia de pasajes", en mi edición del Opus postumum. Anthropos/UAM. Barcelona 1991, p. 55s.). Hasta los Konvolute X-XI, el VII y el I (a partir de mediados de 1799), en efecto, la temática restringida a la Transición estaba más o menos concluida. No es extraño que el propio Kant escribiera a Lichtenberg (1 de julio de 1798) anunciándole para la Feria de Pascuas de Leipzig (o sea, para la primavera de 1799): "algo que tengro entre manos." (XII, 247). 
dicables, en base a la tabla categorial), según el desideratum expuesto en el prólogo de los Metaphysische Anfangsgriüde (IV, 467).

Lo que se propone Kant con tan abstrusas doctrinas no es empero otra cosa que la cumplimentación, también en el ámbito de la fundamentación de la ciencia de la naturaleza, del programa crítico antes citado: todo lo dado externamente, todo lo inmediato, aparece como una imposición y, por ende, como una restricción de la libertad humana, ya sea desde las alturas de la religión, eclesiásticamente administrada, desde la majestad del poder político o desde el rasero de lo empírico, con la presunta obligatoriedad de «atenerse a los hechos». Por eso distingue Kant en la "Arquitectónica de la razón pura" entre cognitio ex datis y cognitio ex principiis. El primero es «meramente histórico" (bistorisch: hoy diríamos "empírico"); el segundo "racional». De aquél se tiene noticia (mero Kenntnis) sólo en cuanto "dado de fuera" (anderswärt gegeben), ya sea - sigue Kant- "por experiencia inmediata, narración o adoctrinamiento». En cambio, el conocimiento racional sólo puede "surgir de la propia razón del hombre" ( $\mathrm{KrV}$ A 836/B 864). La ulterior filosofía idealista, ese gigantesco - y a veces exagerado- canto a la libertad y a la autorreferencialidad del saber y del obrar, tomará buena nota de este repudio kantiano de lo «históricon. De ahí el júbilo de esos "espíritus libres" ante los Metaphysische Anfansgründe. Pues bien, que los callados esfuerzos del anciano de Königsberg a partir de 1796 iban en parecida dirección se muestra en pasajes como el siguiente: «la experiencia no puede ser dada, sino hecha por el sujeto para la representación sensible; y está sometida a un Principio de composición de representaciones empíricas en orden a la unidad de una experiencia posible, cuya forma debe ser pensada a priori por un conceptom. (O.p. XXII, 391). Con todo, es claro que los primeros idealistas irán mucho más lejos que el prudente Kant, el cual da con una mano lo que quita con la otra. Si la experiencia ha de ser "hecha" (gemacht) por el sujeto y no "dada" (gegeben) a éste - como si el hombre fuera algo puramente pasivo, a las resultas de lo que la naturaleza quisiera "enseñarle" desde fuera-, esa construcción tiene sentido sólo como una acción para preparar la recepción de aquello que "sale al encuentroy: la materia de las percepciones, ese resto irreductible e imprevisible que nos recuerda constantemente nuestra finitud. La experiencia se construye sistemáticamente a priori como una omnimoda determinatio, pero exclusivamente en cuanto pensada en favor de la «representación sensible». En cambio, a los primeros idealistas no les interesará tanto la fundamentación de la ciencia natural cuanto la liberación del peso muerto de lo dado, de una materia justamente caracterizada como inerte, para poder pasar a considerarla, bien como un obstáculo que sirva de acicate a la acción moral de una comunidad de seres libres, 
como en el caso de Fichte, bien como una originaria actividad inconsciente y paralela, en gradación inversa de potencias, a la actividad consciente del hombre histórico, religioso y artístico, como en el caso del Schelling de la Identitätslehre.

De todas formas, sería un ejercicio inútil preguntarse por el posible influjo que el Opus postumum hubiera podido ejercer sobre esos dos pensadores, que fueron amigos y creyeron luchar en el mismo frente curiosamente durante el mismo período en que Kant redactara su fragmentaria obra: aproximadamente de 1795 a 1801 , y de la que desde luego apenas tuvieron noticia. Sólo un breve pasaje de la necrológica escrita por Schelling en honor de Kant revela el conocimiento al menos del primitivo título de la posible obra: "Todavía en el año 1801 trabajaba en las pocas horas de libre fuerza pensante (Denkkraft) en una obra: Transición de la Metafisica a la Física, que, de haberle permitido la edad su culminación, habría sido sin duda del más alto interés" ${ }^{8}$. Pero en ese año, como es bien sabido, estaba Kant ya bien lejos de la empresa del Übergang. Sus últimos esfuerzos estuvieron dedicados a un empeño mucho más ambicioso, aunque lamentablemente también mucho menos logrado. En lugar de dar un paso adelante, un Fortschritt desde el "Sistema del Mundo" a la "Física como Sistema", se trataba, en propias palabras de Kant, de un "Regreso a la Filosofía Trascendental" (Rückschritt zur Trans. Philos.: O.p. XXI, 80) que habría de culminar nada menos, más acá incluso de la misma Filosoffa Trascendental, en un "Sistema de filosofía pura en su entero compendio" (System der reinen Philosophie in ihrem ganzen Inbegriffe; O.p. XXI, 146).

¿A qué pudo deberse tan espectacular giro, que hizo incluso creer a los primeros estudiosos del Opus postumum (Albrecht Krause y Hans Vaihinger, como ilustres ejemplos) que esos fragmentos contenían en realidad dos obras bien diferenciadas? Para acercarnos al problema, preciso es primero adelantar algo así como un índice ideal de la obra inacabada. En mi opinión podría dividirse el Opus postumum en cuatro partes relativamente bien ligadas cada una a la siguiente, pero mostrando una clara deriva, de modo que los extremos inicial y final apenas tienen conexión alguna entre sí:

${ }^{8}$ Immanuel Kant. En: Sämtliche Werke (ed. Cotta. Stuttgart / Augsburg 1856-61 = S.W.). I/6, 8 . 
1. A la primera parte, escrita entre 1796 y agosto de 1799 (legajos: fardos IV, II, IX, XII y V), le corresponde de pleno derecho el título primitivo: Transición de los Principios Metafisicos de la Ciencia Natural a la Física, y expondría los caracteres genética y retroductivamente (por decirlo con Kant: mediante un regressus transcedentalis) los caracteres generales de la materia, la tópica de las fuerzas motrices y la demostración de la existencia del éter.

2. El segundo apartado corresponde a los legajos $\mathrm{X} / \mathrm{XI}$ (de noviembre de 1799 a abril de 1800), y en él estudia Kant fundamentalmente el sentido de la ciencia física (un sistema en favor - zum Behuf - de lo empirico), la construcción del objeto (con atención capital al llamado «fenómeno del fenómeno" o "fenómeno indirecto") y la fundamentación trascendental del sistema de las fuerzas.

3. A continuación debería colocarse el legajo VII (primavera-otoño de 1800): el punto de retorno a la filosofía trascendental y, a mi ver, la parte con mucho más importante de todo el Opus postumum, en la que centraré mi exposición. Sus grandes temas son: la revisión de las representaciones del espacio y el tiempo, la doctrina de la autoafección y de la autoposición, y el nuevo estatuto de la cosa en sí.

4. En último lugar vendría el disperso legajo I (1801-1803), que muestra ya una clara decadencia senil, aunque precisamente aquí se aprecie el supremo esfuerzo de Kant: presentar un «Sistema de las Ideas» como autocreaciones de la razón, que habría de ser la culminación de la filosofía kantiana.

Habida cuenta del tema que nos ocupa, podemos dejar sin más de lado las dos primeras partes: las propiamente protofisicas o, en términos kantianos, fisiológicas, aun advirtiendo que hasta el final de los legajos se encuentran dispersas consideraciones sobre esos temas y, al contrario, ya desde 1798 comienzan a hallarse textos fragmentarios sobre temas epistemológicos y metafísicos. La razón para que abandonemos en este trabajo la problemática del Úbergang propiamente dicho es obvia: no es posible reconocer bajo ese rubro ningún influjo importante de las obras de los idealistas. No me consta que leyera por caso a Franz von Baader, el único estuidoso con espíritu filosófico que trata por esas 
fechas justamente de problemas relativos al calórico y al éter'. Las alusiones críticas a un "alma del mundo", aunque contundentes, son demasiado breves como para sospechar que Kant hubiera leído Von der Weltseele, de Schelling; y, en todo caso, corresponden a una época muy posterior (finales de 1800) ${ }^{10}$.

En todo caso, la pregunta que ahora se impone es, claro está:)se debe el profundo giro, la Kehre de Kant, a influencias externas de los continuadores idealistas del "Nuevo Evangelio kantiano" y de sus críticos "compañeros de viaje», como los escépticos, o bien viene requerida por exigencias del desarrollo mismo de las doctrinas del Übergang? A mi entender, ambos supuestos se entrecruzan fecundamente aquí. $Y$ de esta necesidad, a la vez externa e interna, surgirá una refundición (lamentablemente, sólo esbozada) de la entera Crítica de la razón pura. En efecto, los temas del espacio y del tiempo y de la autoafección remiten a la Estética trascendental, los de la autoposición y la cosa en sí a la Analítica, y el Sistema de las Ideas (con el controvertido estatuto de la Idea-Dios) a la Dialéctica.

Veamos primero, muy brevemente, las razones internas de este "paso atrás». El problema inicial del Opus postumum consistía en encontrar el modo de salvar el hiato entre los predicables de la Metafísica de la Naturaleza y la Física experimental. La solución primera, derivada de la Arquitectónica de la primera Crítica

${ }^{9}$ Cf. Vom Wärmestoff, seiner Vertheilung, Bindung und Entbindung, vorzüglich beim Brennen der Körper (1786). En las cit. Sämtliche Werke I/3, 1-180. Es lamentable que Kant no haya tenido noticia del trabajo de este por entonces jovencísimo autor (famoso mucho más tarde por su catolicismo exacerbado, su misticismo y sus posiciones políticas), porque se trata de un extudio muy pormenorizado y rico en referencias exactas, que habría corregido no poco algunas de las afirmaciones «empíricas" de Kant. $\mathrm{Y}$ al contrario, es de lamentar que Vom Wärmestoff saliera el mismo año de $M A$, sin tiempo para que Baader pudiera asimilar la carga filosófica de ese tratado.

${ }^{10} \mathrm{~A}$ través de recensiones (que era casi lo único que leía Kant por esa época) y de conversaciones con Johann Schultz pudo quizá Kant tener noticia de la obra de Schelling. Un pasaje polémico parece ir en esa dirección: "No hay espontaneidad alguna en la organización de la materia, sino sólo receptividad en base a un Principio inmaterial de formación de la materia en cuerpos, que se ejerce en el Vniversum y contiene una omnímoda relación de medios a fines; por ello [se trata] de un entendimiento (pero no de un alma del mundo).» (XXII, 78). La alusión al entendimiento y al Principio inmaterial nos envía obviamente a la temática teleológica de Kritik der Urteilskraft (la Technik der Natur, juzgada reflexivamente como debida a un Entendimiento divino, por analogía con la técnica humana). Igualmente crítico es el pasaje de XXII, 62: «el espíritu que pone en actividad a estas fuerzas (se entiende: las del mundo, F.D.) no es un alma del mundo... sino el Principio viviente de la naturaleza material en general... Considerar a Dios como alma del mundo y, por tanto, como ser hipotético... y basar su unidad en Principios empíricos, supone un concepto de Dios - un concepto puramente racional- absolutamente erróneo." 
era insatisfactoria, pues procedía introduciendo ya de antemano en el seno de la Metafísica un doble concepto empírico: el de materia para el sentido externo, el de la "representación empírica: Yo pienso" para el interno ${ }^{11}$. Dejando a un lado por ahora el muy dudoso estatuto de un "ser pensante» como concepto empírico, en todo caso es claro que la metafísica no puede partir de lo empírico, para pretender luego aplicarse a priori a la fundamentación de lo empírico. Por eso, el Opus postumum ensayará la vía opuesta: la de la espontaneidad del pensar. Pensar - había establecido Kant- "puedo lo que quiera, con tal de que no me contradiga» (KrVB XXVI). Y puesto que la forma del pensar consiste en "determinar un objeto con vistas a lo múltiple de una intuición posible" ( $K r V$ A 254/B 309), cabe inventar (erdichten) predicables en favor de la experiencia de una manera libre - pero no arbitraria: siempre en el marco de un esquematismo ahora extendido a las determinaciones espaciales-. Predicables, en suma, que puedan dar sentido a la experimentación cientifica (cf. O.p. XXII 331). El conjunto de estos predicables -en el que la deducción de la tabla categorial se hace en base a la diádica leibniziana- constituye el Sistema Elemental de las fuerzas motrices de la materia, que nosotros podríamos ver como un anuncio de las teorías constructivistas en teoría de la ciencia. Ahora bien,)qué "objeto" podemos determinar en vistas a lo múltiple de una intuición posible que ya no se quiere particular sino global (experientia qua omnimoda determinatio)? Obviamente, debemos encontrar un concepto no empírico de materia que sirva de base a la experiencia. Tal es el concepto de "calórico" o "éter", cuya existencia intenta Kant demostrar analíticamente mediante un claro argumento ontológico (cf. O.p. XXII, 615) o, según otros pasajes, y con mayor razón, apagógico, en el sentido de que sería imposible construir ningún concepto en la intuición sin suponer la existencia de esa materia trascendental de base, problemáticamente «inventada» en favor de la experiencia: "Cabe admitir a priori la existencia de un éter, es decir postularlo, porque sin él no sería el espacio objeto sensible alguno ni se daría ninguna percepción». (O.p. XXII, 110 $)^{12}$. Ahora bien, dado que se admite que

${ }^{11} \mathrm{KrVA}$ 848/B 876: "wir nehmen aus der Erfahrung nichts weiter, als was nötig ist, uns ein Objekt, teils des äusseren, teils des inneren Sinnes zu geben. Jenes geschieht durch den blossen Begriff Materia (undurchdringliche leblose Ausdehnung), dieses durch den Begriff eines denkenden Wesens (in der empirischen inneren Vorstellung: Ich denke).»

${ }^{12}$ El carácter indirecto de la prueba viene expuesto en XXI 542, XXII 552, 554, 615. Para la afirmación de que esta ?materia? no es hipotérica, sino pensada en función de la posibilidad de la experiencia, ver: XXI 216-218, 223 ("estofa -Stoff- demostrable categóricamente a priori"), 230s., 378, 403, 542, 548; XXII, 598 (aquí, aunque la llama ciertamente "hipotética", lo hace en el sen- 
ese extraño uobjowo trascendentals (y munca major dicho) es por un lado una invención udada por ta ranón" (XXII, 554) y por oura que core objewo ues singular y no un concepro cornún a muctuas cossas" (XXII 554**), deberín seguirse - zumque Kant no lo digga jamás, obviamente- que estarnos aquí on presencia de una

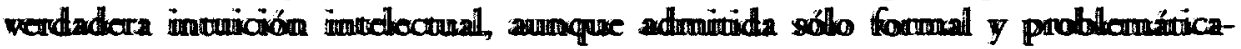

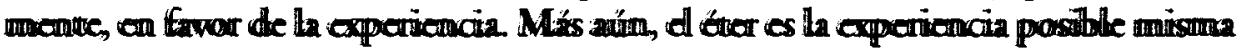

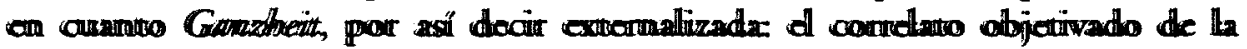

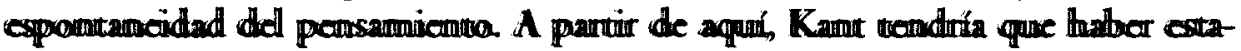

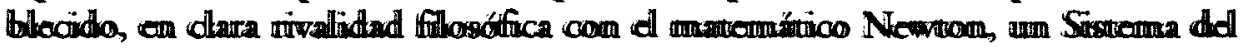

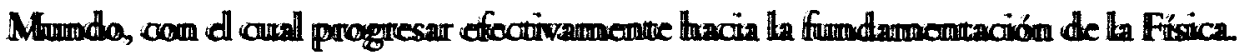

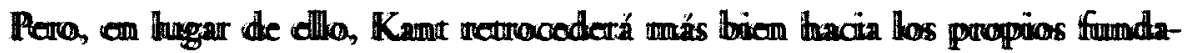

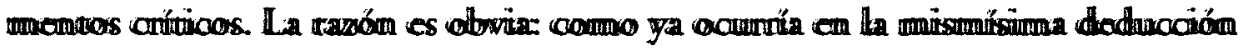

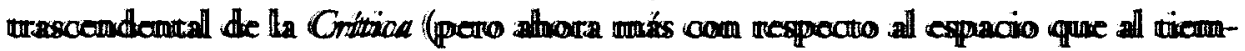

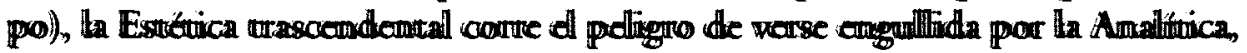

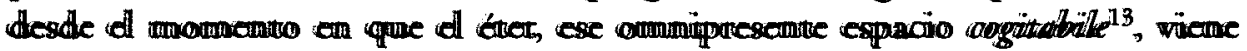

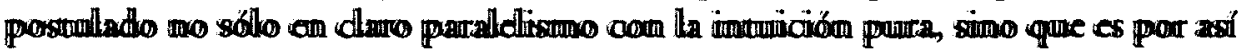

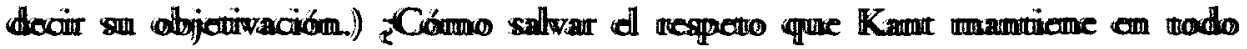

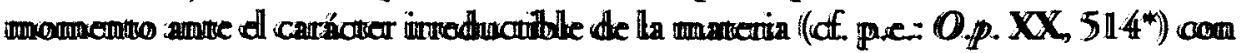

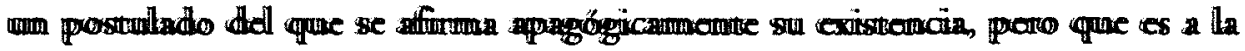

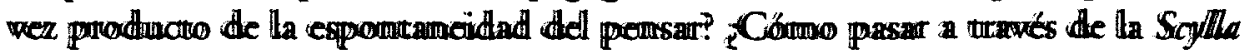

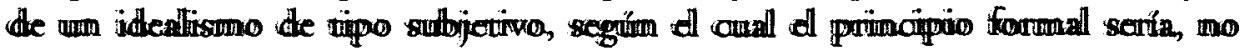

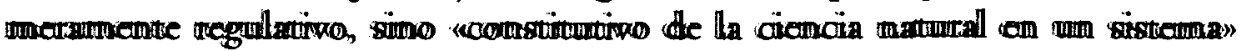

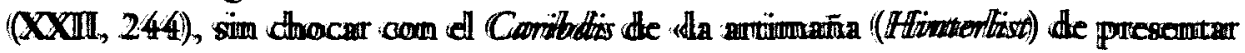

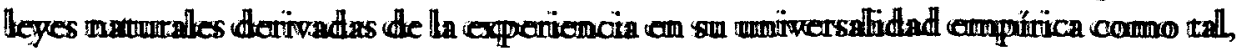

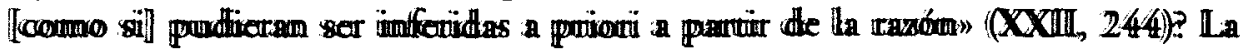

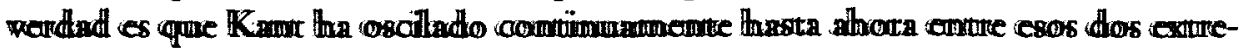

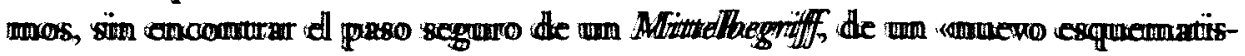
uno" que prerminivera establecer sólidamemte la Cirencia de lla Tramsición. De athí la

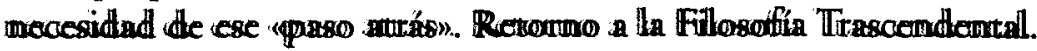

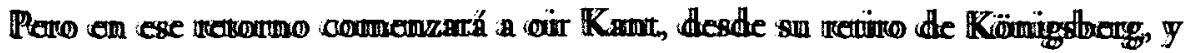

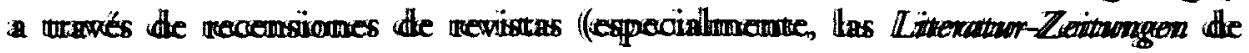

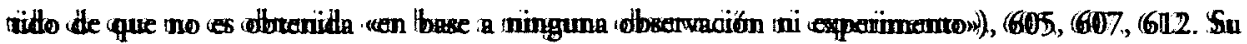

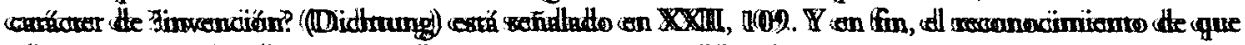

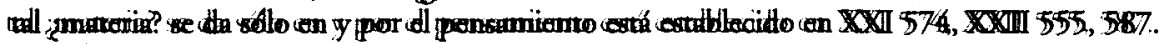

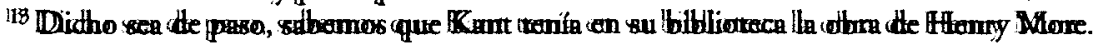




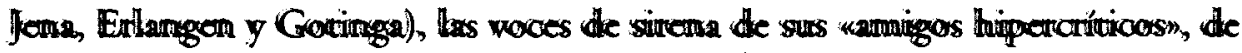

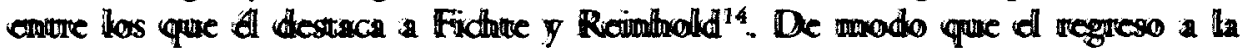

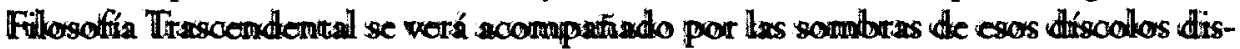
ofipullos (ya que seguramente mo por la llectura dinecta de surs obrass). Em primer

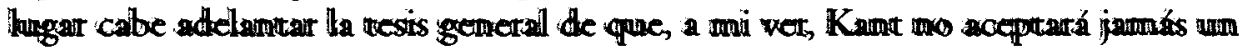
idealismo subieterivizante como el vullgarmente atriburido a Fichte por, sin ir unás

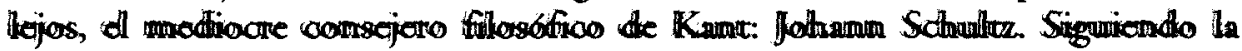

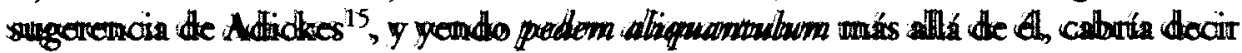

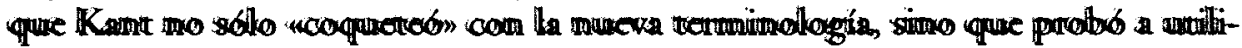

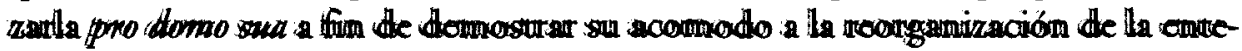

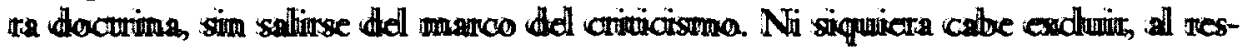

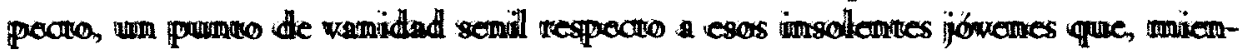

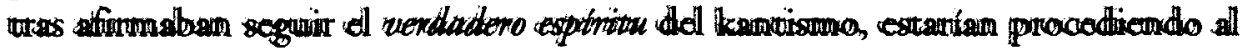
desmannelamiento del crivicismo.

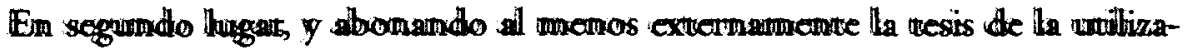

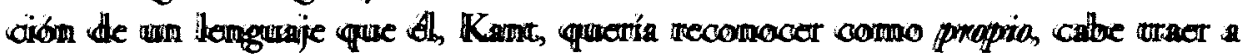

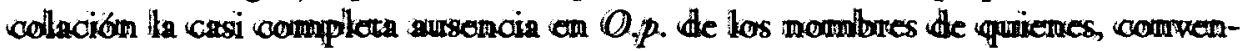

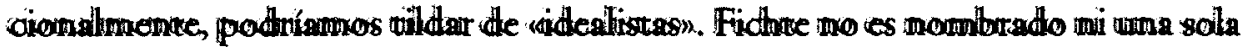

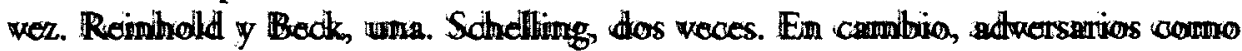

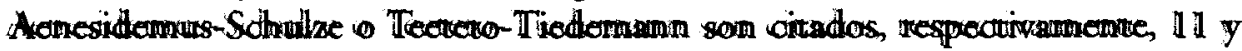

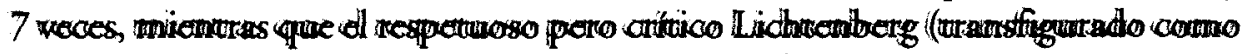

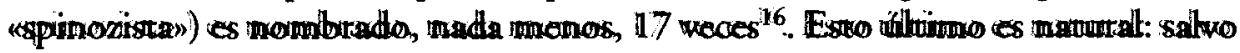

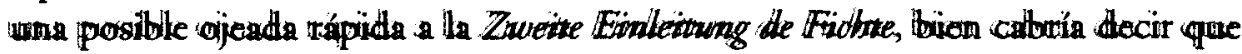

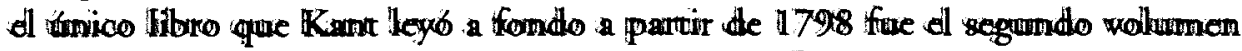
de llos Vermischre Sotmifren de G.Chr. Lichrenbergit7, justo con una lecturra sort-

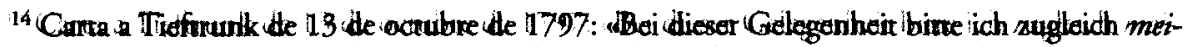

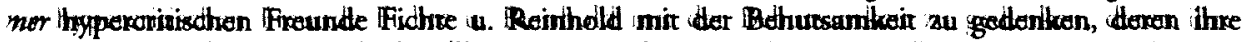

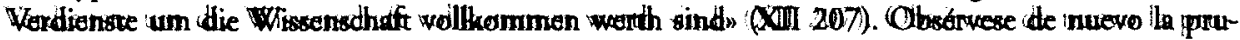
dencia del anciano, que no quaría enemistarse -rodavih- dbiemamente con quienes se confesaban sus disclpulos, per haterodoxos que 'fuexan.

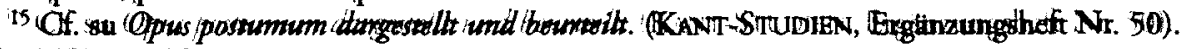
Bowitin 1920, p. 6600.

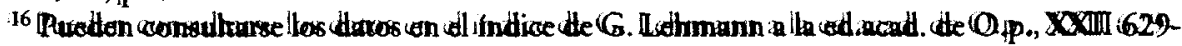
630.

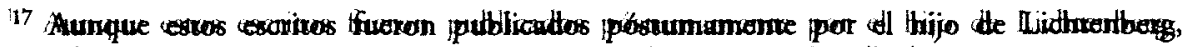

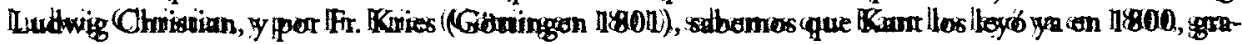

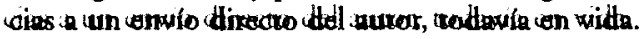


prendente (pero importante para entender el trasfondo del legajo I): el ZendAvesta de Zoroastro (o Zaratustra, como se quiera) ${ }^{18}$. Y será precisamente la lectura "spinozista» que Kant hace de Lichtenberg la que permitirá, para nosotros, acercar los últimos esfuerzos de O.p. a las doctrinas de Schelling, más desde luego que a las de Fichte.

Podemos desde luego desechar cualquier influjo del veleidoso Reinhold en la obra póstuma. Es verdad que el término Vorstellungsvermögen aparece múltiples veces $^{19}$, pero no en el de Reinhold ${ }^{20}$, sino como sinónimo del término usual en Kant: Erkenntnissvermögen, con una matización importante: en la Crítica se nos decía que hay dos Grundquellen des Gemüts, a saber la «receptividad de las impresiones» y la "espontaneidad de los conceptos», atribuida a la «facultad de conocer un objeto por estas representaciones» ( $K r V A$ 50/B 74). Por la primera nos es dado un objeto; por la segunda, viene pensado. Todavía en la tabla de facultades de la tercera Crítica se agrupan bajo el rótulo: Erkenntnissvermögen al entendimiento, la fuerza de juzgar y la razón ${ }^{21}$. Por el contrario, la Vorstellungsvermögen de O.p. "consta de intuición y concepto", y además "comienza por la autoconciencia" (XXII, 420). (Las dos fuentes del ánimo parecen reducidas ahora a una sola, cuyo inicio sería la autoconciencia, identificada en la Crítica con la apercepción, la cual sería no sólo "la condición de toda unidad", sino además ella misma «incondicionadan! ( $K r V$ A 401) ¿¿No es entonces Fichte el que está detrás de esta unificación -impensable en el criticismo ortodoxo-, en lugar del estático y romo Reinhold? No. No lo es. Pero para probar esto debemos entrar in medias res.

${ }^{18}$ Zend-Avesta, Zoroasters Lebendiges Wort, worin die Lehren und Meinungen dieses Gesetzgebers von Gott, Welt, Natur, Menschen, ingleichen die Ceremonien des heiligen Dienstes der Parsen u.s.f. anbehalten sind. Dritter und letzter Theil, welcher Zoroasters Leben, den Ben-Dehesch, zwei kleine Wörterbücher, und die bürgetlichen und gottesdienstlichen Gebräuche bei den jetzigen Parsen enthält. Nach dem Französisch des Herrn Anquetil von J.F. Kleuker übersetzt. Riga 1777 , bey Johann Friedrich Hartknoch. Hartknoch, editor de Kant, envió a éste personalmente el volumen, cuyas huellas se dejan sentir en las últimas partes del O.p. (cf. XXI, 4, 5, 8, 156; 6, 96, 136 ('en estos tres últimos pasos, en conjunción con Lichtenberg!).

${ }^{19}$ Cf. XXI 31; XXII, 43, 67, 91, 92, 94, 97, 58, 352, 420, 421.

${ }^{20}$ Cf. Versuch einer neuen Theorie des menschlichen Vorstellungsvermögens (Prag / Jena 1789). Darmstadt 1963. Al año siguiente, y en el tomo I de los muy influyentes Beyträge zur Berichtigung bisheriger Missverständnisse, aparecería su: Über das Verhältnis der Theorie des Vorstellungsvermögens zur Kritik der reinen Vernunft. Por lo demás, el nombre «Reinhold" aparece, como dijimos, sólo una vez, pero de manera aislada. El pasaje (nada extraño en el O.p.) dice exactamente: «Recantatio, rehabilitatio; Augustini retractatio. Reinhold.» (XXII, 154).

${ }^{21}$ Kritik der Urtheilskraft, Einl. VIII; V, 198. 
El innegable funcionalismo y constructivismo que alienta las páginas del Opus postumum desde los legajos X/XI se debe desde luego más a Beck que a Fichte. Ya en 1794 había anunciado Sigismund Beck a Kant la aparición del tercer tomo de su Erläuternder Auszug. el famoso Einzig möglicher Standpunkt aus welchem die critische Philosophie beurteilt werden muss. En él, explica al maestro, se deduciría analíticamente el entero sistema a partir de la unidad sintética de la apercepción, que Beck entiende como "acto originario de atribución" (ursprüngliche Beylegung). Este audaz matemático compara al respecto la actividad de construcción originaria del concepto de un objeto a través de la categoría con la operación del geómetra, el cual, al construir una figura en el espacio, se da a sí mismo la posibilidad de que exista esa figura. Si tal fuera hacedero en filosofía trascendental, dejaría ésta entonces de proceder analíticamente, por meros conceptos, para rivalizar con la matemática, única que —en el período crítico- es capaz de proceder sintéticamente, por construcción de conceptos. Un pasaje clave de O.p. ${ }^{22}$ rendirá homenaje a esta aportación de Beck: «Que nosotros no comprendemos (einsehen) sino lo que nosotros mismos podemos hacer (machen). Pero primero tenemos que hacernos a nosotros mismos. $\mathrm{El}$ representar originario de Beck». (XXII, 353). No se trata de un mero resumen de la doctrina del discípulo. Muchos otros pasajes - aunque quizá menos contundentes- abonan la idea de que Kant ha hecho suya esa concepción ${ }^{23}$. De este modo ha quedado dinamizado el principio de Reinhold: la filosofía no puede surgir de un mero hecho (Tatsache), sino de una actividad originaria. Es más, dirá Beck: «la realidad efectiva (Wirklichkeit) es el representar originario mismo, del cual se sigue inmediatamente el concepto de objeto" ${ }^{24}$. Ahora bien, Kant aceptará este punto, como sabemos, únicamente por lo que hace a la "existencia" del objeto "éter", o sea: para la entera experiencia objetualizada, y no desde luego para los objetos particulares de la experiencia, para los fenómenos. Lo existente a priori por la actividad originaria no será - como en Beck - el cuerpo que llena un espacio, sino el spatium plenum, o mejor: la plenificación del espacio, con vistas a la recepción en

${ }^{22}$ Que recuerda extrañamente al verum ipsum factum de Vico, de quien, naturalmente, Kant no tenía la menor noticia.

${ }^{23}$ Como señala certeramente H.-J. De Vleeschauwer: «Un souffle nouveau anime son (sc. de Kant, F.D.) propre commentaire: le fonctionalisme de Beck passe insensiblement à Kant." ( $L a$ déduction transcendantale dans l'Oeuvre de Kant. Antwerpen 1937; III, 530).

${ }^{24}$ Einzig - möglicher Standpunct... (Riga, bey J.Fr. Hartknoch [?el editor de Kant!] 1796). Frankfurt/M. 1975, p. 166. Pocas líneas después, añade Beck: "El cuerpo que llena el espacio es realmente efectivo (existe); pues yo obtengo su concepto a partir del representar originario mismo." 
él de la materia de las percepciones. Kant bordea la línea crítica, pero no la traspasa. Es más, el propio Beck se negó a pasar a las filas de Fichte ${ }^{25}$.

¿Por qué este empeño de Kant en evitar a toda costa la caída en el fichteanismo, a pesar del constante uso de expresiones de lcaro sabor fichteano? Pero para empezar, este uso no debiera sorprendernos, ya que su origen se halla, en germen, en la propia obra kantiana. Selbstbewusstsein es expresión frecuente en la Critica ${ }^{26}$. La idea de la experiencia qua omnimoda determinatio y, por tanto, como existencia que "acontece por medio de la razón" aparece ya en una Reflexion de los años $80^{27}$. La posición absoluta o Setzung está ya, como es notorio, en la Einzig möglicher Beweisgrund de 1763 y, desde luego, en la famosa definición de la primera Crítica: "Ser... es meramente la position de una cosa, o de ciertas determinaciones en sí mismas." (A 598/B 626). Y ya en una Reflexion de 1771 se dice: "Lo que está puesto en sí mismo (an sich selbst gesetzt), existe" ${ }^{28}$.

Además, y sobre todo, había fuertes razones personales -en absoluto descartables, en esta época- para que Kant se negara a seguir al arrogante discípulo, al "titán de Jena". Fichte no tuvo la precaución (como hiciera en cambio Beck) de explicar en sus cartas a Kant los puntos fundamentales de la nueva doctrina. Se limitó a enviar periódicamente ejemplares de sus obras al maestro, que prestó nula atención a esos trabajos. Por lo que sabemos a partir del Loses Blatt $L I^{29}$, Kant ni siquiera desató un paquete que contenía presumiblemente obras de Fichte y quedó olvidado en un rincón de la antecámara de su casa. La única noticia indirecta que tenemos del desconocimiento -más que conocimiento- de la Grundlage por parte de Kant se halla en una carta a Tieftrunk de 5 de abril de 1798:" ¿Qué opina Vd. de la doctrina general de la ciencia del Señor Fichte? Me ha enviado hace tiempo un libro ( $(0$, pero lo he dejado por encontrarlo largo, y porque me distraía de mi trabajo, y ahora (lo) conozco por la recensión de A.L.Z. ${ }^{30}$ Por ahora no tengo

${ }^{25}$ Sabemos que Fichte había visitado a Beck para que se uniera a él. En lugar de hacerlo, Beck se apresura a comunicárselo a Kant, para congraciarse con el maestro (carta de 24 de junio de 1797; XII 174).

${ }^{26}$ Según la cuenta de Hans Amrhein (Kants Lehre vom «Bewusstsein überhaupt» und ihre Weiterbildung bis auf die Gegenwart. KANT-STUDIEN; Ergänzungsheft 1. Würzburg 1909), ese término aparece 17 veces en $\mathrm{KrV}$.

${ }^{27}$ Refl. 5710; XVIII 332.

${ }^{28}$ Refl. 4396; XVII 531.

29 Recogido por Adickes, op.cit., p. 606, n. 2.

${ }^{30}$ Se trata naturalmente del órgano del unuevo evangelion: la Allgemeine Literatur-Zeitung de Jena. La recensión apareció en los núms. 5-9 de 1798. 
tiempo libre para ocuparme de él». (XII 241). (¡Y ello en una época en la que Kant comienza justamente a usonan" a Fichte! Es más, recuérdese que al inicio hablamos, con Kant, del esuplicio de Tántalo» que representaba para él la redacción de la obra póstuma (según carta a Garve de 21 de septiembre de 1798). Pues bien, quien castiga en esta época al desdichado Kant-Tántalo parece ser (el propio Fichte! Apenas tres meses antes de esa confesión, el 1 de junio de 1798, Abegg visitó a Kant, y le entregó una carta de Fichte. Como relata el propio Abegg, el anciano aprovechó la ocasión para explayarse sobre la novisima doctrina: «No he leído todos sus escritos, pero sí lé́ recientemente la recensión en la Literaturzeitung de Jena: al principio no logré entender exactamente de qué se trataba ${ }^{31}$; la leí por segunda vez, creyendo que entonces podría entender algo, pero en vano. Fichte te presenta una manzana que no te deja comer. Lo mismo daría tratar del problema: mundus ex aqua? Se queda siempre en las generalidades sin dar nunca un ejemplo, pero tampoco (lo que es peor) podría darlo, porque aquello que correspondería a sus conceptos generales no existew ${ }^{32}$. Esa manzana es, claro está, el Yo. Y Kant se va a esforzar por llenarla de la carne palpitante del sum personal, anclando el pensamiento en la sólida base del ser.

De todas formas, la inquina de Kant hacia Fichte tenía sus motivos. Mientras que éste insistía en: "que mi sistema no es otro que el kantianow ${ }^{33}$, a renglón seguido decía que ello era respecto a la Sache selbst, no a la letra del viejo, y que por ello: «Mis escritos no pretenden explicar a Kant, no ser explicados por É; deben tenerse en pie (stehen) por sí mismos, y Kant queda por completo fuera de juegow. (S.W. I, 420s.). Y si el de Königsberg no leía esas obras, allí estaba el fiel Schultz para recordarle esos pasajes. Pero la gota que colmó el vaso (o el

${ }^{31}$ Esto no es nuevo en el viejo Kant. Parece que -como suele ocurrir con la edad-tenia gran dificultad para entender doctrinas ajenas, y menos para aceptarlas. Asi, ya en 1794 le confiesa a Beck que no entiende sus usuperfinas escisiones de hilos* (überfeine Spatrungen der Fäden; nosotros diriamos «de cabellosw, F.D.) respecto a la Enkenntnisuermögen, y le desea suerte en esa empresa. (Carta de 1 de julio de 1794, XI 515).

32 XIII 482; subr. mío (la carta de Fichte es de 3 de mayo de 1798). También en la ya citada carta a Tieftrunk de 5 de abril de 1798 dice Kant algo parecido, y con un inciso bien significativo, que yo subraya: rla recensión (decididamente benevola) que se ha hecho me deja la impresión de una especie de fantasma: cuando se cree haberlo cogido, no encuentra uno ante sí ningún objeto, nada más que el yo mismo, o mejor, en el yo nada más que la mano extendida para coger el objeto. - La simple autoconciencia, considerada realmente tan sólo seguin la forma del pensamiento, sin materia, sin más que la reflexión, pretendiendo elevarse incluso sobre la lógica, produce una extrafia impresión en al lector..

${ }^{33}$ Erste Einleitung. Sïmdiche Werke. Ed. I.H. Fichte (= S.W.) I, 420. 
lago) en el que nadaba Kant-Tántalo fue proporcionada por la recensión del Entwurf der Transscendentalenphilosophie de J.G. Buhle, aparecida en una revista que Kant sí leía: la Erlanger Literaturzeitung, el 11 de enero de 1799. Allí se dicen cosas realmente graves: "Kant es el primero en haber enseñado (der Lehrer) la filosofía trascendental, y Reinhold el excelente divulgador de la doctrina crítica: pero el primer filosofo trascendental es sin duda Fichte. Fichte ha realizado (realisirt) el plan esbozado (entworfnen) en la Crítica, y ha llevado a cabo sistemáticamente el idealismo trascendental insinuado (angedeuteten) por Kant. (De ahí que sea natural el deseo del público de que el fundador de la Crítica se pronuncie oficialmente sobre su discípulo más digno (würdigsten), el autor (Urheber) de la filosofía trascendental! ${ }^{34}$. Esto era realmente demasiado. Y Kant se desquitó, en unos momentos en que todo el mundo (incluyendo la remota Königsberg) sabía que Fichte estaba bajo la sospecha de ateísmo que le costara la cátedra de Jena. Kant eligió además para su declaración el "órgano oficial" del kantismo: la Allgemeine LiteraturZeitung. El 28 de agosto de 1799 (recordemos: en el período en que con más fuerza y frecuencia aparecen expresiones aparentemente fichteanas en O.p.), y en el número 109 de la revista, apareció la Erklärung in Beziehung auf Fichtes Wissenschaftslehre (XII, 370-371). Sin duda, una mancha que ensucia los últimos años del anciano. Él, que había dicho que no hay autores clásicos en la filosofía, afirma ahora que hay que tomar su obra al pie de la letra, sin intentar interpretarla, y que su doctrina es un sistema, no una propedéutica ${ }^{35}$. Por lo demás, los reproches van in crescendo, hasta el grand finale: «Dice un refrán italiano: 'Dios nos libre de nuestros amigos, que de nuestros enemigos ya sabemos guardarnos nosotros'». (XII, 371). Cuatro años después, al borde de sus fuerzas, y ya colmados de allotria y senilia los últimos textos de O.p., el anciano intentará, al menos en la escritura, usurpar el puesto del odiado discípulo, presentando patéticamente el título de una obra que, naturalmente, nunca escribiría y que dejó sin firmar:

34 XIII 542s.

${ }^{35}$ En el legajo IX, pliego IV (XXII, 240), escrito entre enero y febrero de 1799 (y por tanto, inmediatamente después de la recensión del libro de Buhle), dice Kant: «Esta Transición no es meramente propedéutica, pues éste es un concepto fluctuante que concierne sólo a lo subjetivo del conocimiento.m (subr. mío). No cabe duda pues de que por entonces estaba ya rumiando la Declaración contra Fichte. 


\author{
Philosophie \\ als Wissenschaftslehre \\ in einem vollständigen System \\ aufgestellt \\ von. (XXI, 155). ${ }^{36}$
}

Desde luego, hay que reconocer que todas éstas son razones (por llamarlas de algún modo) externas. ¿Es posible que, a pesar de todo, Kant cediera a la nueva doctrina y se apoderase a la chita callando (stillschweigend, diría un alemán) de ésta? Ello me resulta altamente improbable, a la vista de los textos mismos. Analizaré para ello brevemente sobre todo los legajos VII y I, correspondientes a lo que yo he denominado como Tercera y Cuarta Parte del Opus postumum.

Vaya por delante un punto que tengo por altamente relevante: normalmente, lo que Kant califica de "idealismo" a secas o "egoísmo" tiene poco que ver con las doctrinas de Beck, Fichte o Schelling, sino que se remonta más bien - como desde la perspectiva del propio Kant es bien lógico- a lo criticado en la Refutación del idealismo de la segunda edición de la Crítica, esto es, a un cierto berkeleysmo difuso (según la conocida acusación de Garve y Meiners con respecto a la primera edición), que él cree ver ahora representado en Lichtenberg (junto al "spinozismo" de éste) (y aún en el sensualista Tiedemann) ${ }^{37}$. A éste se refiere muy probablemente un pasaje polémico: "El idealismo no hace a este respecto diferencia alguna entre el Principio de los objetos en el fenómeno, que el sujeto se representa en sí mismo, y la experiencia. La idealidad de lo empírico,

${ }^{36}$ No deja de ser extraño este intento de reescribir so modo una Wissenschaftslehre (por más comprensible que sea desde el resentimiento y aun la envidia), dado que el único pasaje de O.p. en el que Kant ataca frontalmente a Fichte (sin nombrarlo) despacha despectivamente a la Doctrina de la Ciencia de esta guisa: "Una Doctrina de la Ciencia en general, en la que se abstrae de la materia de ésta (los Objetos de conocimiento), es la lógica pura; y constituye un estéril girar en círculo con los conceptos el pensar otra Doctrina de la Ciencia aún más elevada y universal, la cual no puede contener de suyo más que lo científico del conocimiento en general (su forma)." El pasaje está escrito entre mayo y junio de 1799, según a datación de Adickes.

${ }^{37}$ Kant suele citarlo (como a Schulze) por el título de su obra principal: Theätet oder über das menschliche Wissen; ein Beytrag zur Vernunftkritik (1794). Quizá la fuente de la confusión con el idealismo esté en el título de la obra de 1798 (repárese en la fecha): Idealistische Briefe, en respuesta a las objeciones a su Teeteto. De todas formas, el principio supremo es para Teeteto: Ich habe Bewusstsein (p. 2; cit. XXII, 815); y Tiedemann defiende un sensualismo "enclaustrado" en esa conciencia, que para Kant - no muy ducho, como es sabido, en historia de la filosofia-- bien podría confundirse con Berkeley. 
comparada con la realidad." (XXII, 469)). La última frase debe entenderse, a mi ver, como urealidad empírica, lo cual estarta de acuerdo con la propia doctrina (el idealismo trascendental como realismo empúrico), y con la refutación del idealismo dogmáticice en b Crítica (B 274s.).

Por lo que respecta en cambio a Lichtenberg el tratamiento de Kant es mucho más respetuosa Y ello, no súlo por los servicios que bas obras del gran sabio de Göxtingen habian prestado a Kant para sus estudios provocientíficos, y por ed ucontagion que el propio Lichtenberg muestra de grado respecto al criticismo, sino también por su araque despiadado contra Fichte en los Vermeisctore Sotmifture (11, 102). Así, las frecuentes alusiones de Kant a Spinoza, en cuyo Dios intuiriamos todas las $\operatorname{cosas}^{38}$, provienen de lichrenberg, que habia defendido una furura "Uniwersat-Retigionn como uspinozismo purificadon, a donde conduciría necesariamente uuna rasón dejada (überlassene) a sí solam. (11, 33). Un ideal éste al que parece tender también Kant, unienda a esas consideraciones dististas. las del mismisimo Zaroastro: «La fillosofia] tras[cendental] es el acto de conciencia mediante el cual el sujero llega a ser autor (Unbetar) de sí misma; del moda, partiendo del objeto total de la ráón técnico-práctica y de la ético-prác-

${ }^{38}$ Es vendad que en b Dissertatio habra atribuido Kant esa concepción a Malebranche, según b tradición, aunque, de sex estrictos, debiéramos remitimos en última instancia a los Hechos de los Aproules 17,28, donde San Pablo dice a los atenienses que en su dios desconocido - para el empero, bien conocido- uvivimos y nos movemos y existimosm. Por cierto, de manera bien poco ontodoxa, Kant trastada la famosa máxima al usujeto del imperativo categóricon, al cual primero llama Dios, para enseguida afirmar. «En él (en el hombre [mo se puede tratar de un bassus calami por lo que sigue, y que yo subraya, F.D.l que piensa moralmente según mandamientos del deber de nosorros mismos) vivimos (sentimus), nos mowemos (agimus) y existimos (existimus). (XXII, 55). Parece en efecto un bucle, que conectarfa con la ya citada doctrina critica sobre b raón libue y pública El sujeta, en primera persom del phurd, seriamos nosouros los bombres de carne y huesas ese usem denuro del cual vivimos seriti el shambre interiom, del que ya habla b Crítica: uel sabio (de) estoico), m, que wes un ideal, esto es un hombre existente sólo en pensamientos, pero que es plenar mente congruente can b idea de h sabiduriam (A 569/B 597); y por fia, unosotros mismoss: la fuente de b que maman los mandamientos del deber, y que se confundiría en su phuralidad can el hombre (ih ingo Dei agustiniana?) interior, seria la uidea de la humanidad, que el hombre lleva en su alma como prototipo (Unbild) de sus acciones, (A 318/B 374). Sea como fuere, y como señata-

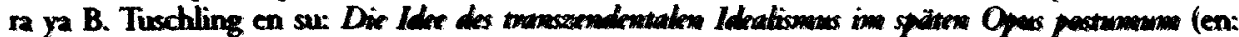
Finm fir Philosephir Bad Hombung (Hg), Obergang. FrankfurtM. 1991, p 121, n. 46), campoco viene mada de extraño que Kant aluda al respecto a Spinoza. Basta ver h pr. 15 de b Pars 1 de ba Exthicar. Quicquid esr, in Deo est, 8 nihil sine Deo esse, neque concipi poressm. (subr. mio).

39 $\mathrm{Cf}$. a respecto b estrecha conexión que hace Lichtenberg entre Spinoea y el Drismas en: Venmicothe Solnifiem, II, 32. 
vica, lloga a ordenar en Dios todas bs coses como en un sistema. (Zoroastro) (XXII, 78). En todo caso, y como se aprecia por d pasaje anterior y el citado en nota 37, Kant dará audamente b vucha al spinoxismo de lichtenberg: «No es que nosotros - como se imagina Spinoea - nos intuyamos en b divinidad, sino al revts: introducimos nosotros nuestro concepto de Dios en los objetos de intuición pura, en nuestro concepto de b filosofía trase.* (XXII, 59). Por eso, en vez de innuirnos y de ver todo en Dios, en vez de ser, movernos y existir en A, habría que decir más bien lo contrario: uess Dews in mobion (XXII, 130). Obsérvese por lo demís cuán lejos llega d último Kant con esta línea de argumentación: ula idea Dios (mo de Dios) pues sería entonces un Objeto, algo pensado como existente. Dies no es una cosa subsistente fuera de mi, sino un pensamiento propio mío. Es absurdo preguntar si hag un Dios. (XXI, 153; cf. XXI, 145). ¡Y pensar que a Fichre lo expulsaron de su cáredra de Jena por defender una idea de Dios como worden moral del mundow?

Sea como fuere, Lichtenberg defiende un uidealismo dogmátricom que Á riene por irrefurable, y que remite desde luego más al escepticismo del Enexidemo (y a su través, a Hume) que a Fichte o Schelling: "Tener la sensación de algo fuera de sí es una contradicción; sensaciones sólo las tenemos en nosotros; aquello de lo que nosotros tenemos sensación es una mera modificación de nosotros mismos, o sea, lo que sentimos (empfinden) estŕ en nosotros.* (11, 66s.). Por eso, y literalmente contra la kantiana "Refutación (Widerlegung) del idealismo", afirma también: "Es absolutamente imposible refutar (widerlegen) el idealismo, porque nosotros seguiríamos siendo en todo caso idealistas aun cuando existieran objetos fuera de nosotros, porque es imposible que podamos saber algo de esos objetos.» (II, 62s.). Pues bien, la postura kantiana al respecto es en cambio clarísima: «Hay un mundo. Ni el idealismo (Lichtenberg, al que acaba de cirar; F.D.) ni el goismo trasc. ${ }^{\text {[I }}$ pueden suprimir la realidad objetiva de las represen-

- Cf. p.e. XXII, 105: „El concepto de Dios es b idea que se hace d hombre, en cuanto ser moral, de un ser moral supremo en una rebción según los Principios ded derecha.

4l Adviértase algo que en b uaducción puede perderse: Kant habla primero de Idealism, sin

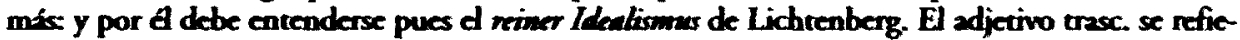
re coclusivamente a h doctrina lamada $E_{8}$ iom, con h que bien podrí aludirse desde lucgo al pasaje de b «Refuración” donde habla Kant del: eidealismo problemírico de Descartes, que tiene por indudable sólo una afirmación empírica (escertio), a saber: Yo sogr (KrV B 274). Ahora bien, puesto que tanto d idealismo problemático como el dogmático son tildados alli de idealismo marerial, bien podríamos pensar que el blanco de la crfica, o sea el egoista urscendental, serfa 
taciones sensibles ni, por consiguiente, la experiencia; es absolutamente idéntico decir que hay tales objetos o que yo soy un sujeto, pues a ello conduce el estado de mi representación: una tal cadena legal de lo múltiple, que llamamos experiencia... La experiencia es la aproximación asintótica a la completud empírica de las percepciones. Experiencia (no en plurali) completud del sistema de las percepciones.» (XXI, 53). El pasaje es de 1801: es evidente pues que Kant ha mantenido con toda coherencia la Grenzlinie crítica hasta el final de su vida pensante.

Ahora bien, es claro que, de haber conocido esas críticas, Fichte podría haber argüido, con toda razón, que él poco tenía que ver con ellas. En la Zweite Einleitung (la única obra suya que posiblemente ojeara Kant) habla Fichte de que el final de la filosofía (y el consiguiente paso a la Ciencia: el Saber Absoluto) se dará con el Yo "en cuanto idea", o sea con el "ser racional" (Vernunftwesen), el cual lo es, por un lado, por haber expuesto (dargestellt), o sea construido ${ }^{42}$ perfectamente en sí y en el mundo la razón universal. Mas incluso en ese estadio final, dice Fichte: «El mundo sigue existiendo en esta idea, en cuanto mundo en general, como sustrato, con leyes determinadas, mecánicas y orgánicas; sólo que estas leyes son absolutamente apropiadas para exponer el fin final (Endzweck) de la razón" ${ }^{43}$. El mundo es pues en Fichte, naturalmente real, y existe fuera de nos-

más bien Fichte, con su "Yo soy Yo" (malentendido desde luego por Kant, como malentiende igualmente a Descartes). En todo caso, el "candidato" a "egoísta" estaba ya anunciado avant la lettre en el famoso Beylage de David Hume über den Glauben oder Idealismus und Realismus. Ein Gespräch, de Jacobi: «El idealista transcendental ha de tener pues el coraje de afirmar el más fuerte idealismo que jamás se haya enseñade, e incluso no retroceder ante la acusación de egoísmo especulativo, porque le será imposible afirmarse en su sistema si intenta zafarse de esta última acusación.» (Breslau 1787, p. 229). Naturalmente, el aludido aquí es Kant, al que incita Jacobi a "saltar las bardas de su corral» (como diríamos con nuestro Antonio Machado), aunque luego fuera Fichte quien recogiera el desafío... para negar que él, Fichte, represente tal Egoismus (cf. Zweite Einleitung ? 12; 1, 517). De modo que, contra toda interpretación anacrónica, hay que insistir en un hecho palmario: el último Kant se está midiendo contra adversarios por él conocidos desde tiempo, como Lichtenberg o Jacobi, y no con sus "amigos hipercríticos", cuya doctrina conoce sólo de oídas.

${ }^{42}$ Como es sabido, Darstellung es un término "técnico" para todo el idealismo, desde Kant, y equivale a Konstruktion (en Kant, construcción del concepto en la intuición, cuyo resultado es un objeto de experiencia). Por ello, bien puede entenderse aquí que, en Fichte, el ser racional (que desde luego ha dejado ya de ser un mero individuo, puesto que por nada está limitado) ha construido perfectamente en sí mismo la razón universal (o sea: ha expuesto su concepto en la intuición), y se identifica plenamente con ella (recuérdese en todo caso que se trata de una "idea", con la que la filosofía deberá finalizar in infinitum, convirtiéndose así en Sabiduría; y el hombre, añadiríamos, en Dios).

${ }^{43}$ S.W. I, 516. 
otros, en cuanto individuos; pero a la vez está contenido íntegramente en la Idea-Yo, o mejor: deberá estarlo, al final de los tiempos (puesto que él reconoce que «a esta idea sólo nos iremos acercando en un proceso infinitom: I, 516) ${ }^{44}$.

Si ahora cambiamos la Idea-Yo por la Idea-Dios ${ }^{45}$, parece que podríamos establecer una estrecha cercanía, al menos aquí, entre Fichte y Kant. Éste reconoce en efecto que: «El concepto de Dios es la idea de un ser moral... Este no es una cosa hipotética, sino la pura razón práctica misma en su personalidad, y con sus (ihren) fuerzas motrices en vista de los seres del mundo y de sus fuerzas. Libertad bajo leyes coactivas de la razón pura." (XXII, 118). Dejando a un lado la extrañeza producida por esta identificación de las "fuerzas motrices» con las «leyes coactivas» de la razón (mandatos derivados obviamente de la ley moral), parece claro el paralelismo entre el "mundo" legaliforme kantiano y el "mundo" fichteano, con sus leyes perfectamente adaptadas al fin final de la razón. Pero sólo lo parece. Jugando de vocablo, podríamos decir que un mundo separa esos dos «mundos». En primer lugar, la Idea-Dios no es nunca en Kant la Idea-Hombre. El hombre sirve más bien de copula entre Dios y el mundo ${ }^{46}$ : “Dios, el mundo y el concepto del sujeto que los une, el cual da a esos conceptos unidad sintética (a priori),

${ }^{44}$ Kant parece reconocer esta idea fichteana de aproximación infinita cuando afirma que "el ideal de la razón ético-práctia" sería «el arquetipo y el arquitecto del mundo, aunque sólo pueda servir como en una infinita aproximación» Pero, como de costumbre, a la máxima cercanía aparente corresponde un alejamiento real. Pues inmediatamente añade, con un sutil cambio del famoso dictum paulino (I Cor. 13, 12): "Lo intuimos como en un espejo: nunca cara a cara." (XXI, 33; subr. mío).

${ }^{45}$ El propio Kant se pregunta «si esta Idea, producto de nuestra propia razón, tendrá realidad (Realität) o si será meramente un Gedankending (ens rationis)." (XXII, 117). Adviértase que un mundo separa el Vernunftwesen fichteano (que Kant llamaría ens rationis ratiocinatae) del Gedankending (el cual serfa más bien un ens rationis ratiocinantis). De todas formas, como se verá en el texto siguiente, citado en el corpus del ensayo, Kant se inclina desde luego del lado del Vernunftwesen: Dios (como por demás las Ideas de Hombre y de Mundo) no son sólo productos de la razón, sino que en ellas se produce y genera a si misma la razón.

${ }^{46}$ Véase al respecto el esquema que Kant se proponía desarrollar para culminar su "sistema de la filosofía trascendental en tres secciones»:

"Dios, el mundo - universum - y Yo mismo: el hombre como ser moral.

Dios, el mundo y el habitante del mundo: el hombre en el mundo.

Dios, el mundo y aquello que piensa a ambos en real interrelación: el sujeto como ser racional del mundo.

El medius terminus (copula) en el juicio es aquí el sujeto que juzga (el ser pensante del mundo: el hombre en el mundo). Sujeto, predicado, cópula.» (XXI, 27).

Por usar la terminología cartesiana: la realitas obiectiva de Dios es la pura espontaneidad; la del mundo, pura receptividad; la del hombre, una espontaneidad en favor de la receptividad. Así 
en cuanto que la razón misma hace esa unidad trascendental. ... Dios, el Mundo, y Yo; Dios, el Mundo, y el Espiritu del hombre como aquello que enlaza los dos primeros." (XXI, 23). En segundo lugar, y en coherencia con lo sostenido en las "Antinomias", subsiste una irrebasable diferencia entre Dios, el Mundo y el Yo, como se advierte en este texto decisivo: «Dios, el mundo y la conciencia de mi existencia en el mundo, en el espacio y el tiempo. Lo primero es noumenon, lo segundo phaenomenon, lo tercero causalidad de la autodeterminación del sujeto en la conciencia de su personalidad, es decir de la libertad en la relación de la totalidad de los seres en general.» (XXI, 24). Ello es perfectamente lógico, y profundamente antifichteano: si no se diera esa diferencia no podría hablarse de una unidad sintetica, es decir, entre extremos heterogéneos.

Pero es más: Kant establece esa relación desde un punto de vista estrictamente formal, logico, sin que ella tenga nada que ver con la existencia de esas Ideas: "Dios y el mundo son los dos Objetos de la filos. trasc. y (sujeto, praed[icatum] y copula) es el hombre pensante. El sujeto que los enlaza en una proposición. Se trata de relaciones lógicas en una proposición, que no concierne a la existencia de los Objetos, sino que se limita a lo formal de las relaciones, para llevar estos Objetos a unidad sintética.» (XXI, 37). Naturalmente. De lo contrario, estaríamos saltándonos la prohibición establecida por la "Antinomia" de la Critica. La Idea de Mundo es desde luego una mala idea, ya que el mundo no deja de ser un conjunto de fenómenos, aunque nosotros lo pensemos como una determinación omnímoda, en vista al concepto problemático del éter o, en estos pasajes, como correlato protofísico del Objeto trascendental (el cual, desaparecido en la segunda edición de la Crítica, vuelve ahora por sus fueros).

Por el contrario, Fichte cree firmemente en la realizabilidad, y más, en la realización histórica de esa Idea-Yo con la que culminaría el sistema. O dicho de otro modo: Fichte subordina de tal modo la razón teórica (volcada a la naturaleza) a la razón práctica que aquélla deberá acabar por ser la exposición o Darstellung perfecta de ésta. Kant sigue defendiendo en cambio, y con más vigor

es como la Idea-Hombre se constituye ella misma como Úbengang: paso entre la espontaneidad y la receptividad, entre la libertad omnímoda divina y el «mecanismo" de la naturaleza. Pero, por su realitas formalis, o sea en cuanto actividad existente-pensante, el Hombre puede constituirse en el locus de las dos ideas. 
y claridad que antes ${ }^{47}$, el estatuto fundamental de la razón especulativa (o dicho de otro modo: ratifica la primacía de la primera Crítica, ahora tendencialmente identificada con el Sistema de la Filosofía Trascendental en su conjunto, sobre las otras dos). En efecto, sólo dentro de este marco teórico establece, como si se tratase de dos especies del género "razón", la subordinación de la «razón técnicopráctica" (que parece sustituir así al Juicio reflexionante teleológico) a la "razón ético-práctica». Pero esa subordinación es responsabilidad exclusiva del hombre. Cada una de las regiones tiene su legalidad específica. Tomadas cada una de por sí, y vistas desde la suprema teoricidad de la razón, podría hablarse incluso de una equiparación, según prueban pasajes como el siguiente: «La atracción newtoniana por el espacio vacío y la libertad del hombre son conceptos recíprocamente (einander) análogos. Son imperativos categóricos. Ideas." (XXI, 35). Consideradas las cosas desde el mundo actual de la tecnociencia, es muy sugerente que el último Kant haya acercado la región física al quehacer técnico del hombre ((la atracción newtoniana, vista como el resultado de construcciones tecnomatemáticas, al modo de un imperativo categórico técnico, y ya no simplemente hipotético!), de igual modo que el ámbito otrora contemplativo, metafísico de lo divino quede adscrito al obrar moral humano. Por lo demás, ambas funciones quedan siempre exquisitamente separadas: «En la razón técnico-práctica están la habilidad y las artes. En la ético-práctica, los deberes.» (XXI, 12). Y también: "No es la razón técnico-práctica, sino la ético-práctica la que absuelve o condena.» (XXI, 13). A renglón seguido escribe además Kant un texto dantesco, quizá el más terrible y «hobbesiano» que haya salido de su pluma, y que deja bien a las claras que la naturaleza nunca servirá de perfecta exposición o campo de construcción de la razón ética: «La naturaleza procede con el hombre despóticamente. Los hombres se destruyen mutuamente como lobos; las plantas y animales crecen unos a expensas de otros, o se ahogan mutuamente. La naturaleza no se preocupa de los cuidados y atenciones que ellos necesitan. Las guerras des-

${ }^{47}$ Parece incluso que Kant olvide ahora lo que escribiera al inicio de la Crítica de la razón práctica, y que constituiría desde luego la fuente de la que bebería Fichte: „El concepto de la libertad... constituye pues la clave de bóveda del entero edificio de un sistema de la razón pura, incluso de la especulativa) (V, 3). Sin embargo, convendría hacer una distinción aquí. Una cosa es el rango de la libertad, que en $O . p$. sigue siendo incontestablemente el valor supremo, y otra bien distinta el estatuto explicativo, filosófico, de la razón. Ni la razón práctica es, sin más, la libertad (cosa que el primer Fichte tiende a confundir), ni ese uso de la razón se explica y fundamenta por sí mismo, sino por el ejercicio especulativo, aunque éste se halle a su vez orientado por el fin e interés último de la razón humana, desde luego práctico. Hegel será a este respecto mucho más fino (y por ende, más kantiano) que Fichte. 
truyen aquello que a lo largo del tiempo ha levantado y cuidado la industriosidad humana." (XXI, 14). Así pues, al irenismo utópico fichteano se opone tajantemente la prudente sobriedad, y más: el hondo pesimismo de Kant. Él no se hace ilusiones desde luego sobre el futuro del mundo, ni sobre el destino del hombre.

Pues bien, si entre ambos pensadores existe una oposición frontal con respecto a la idea del final de la filosofía (y del mundo, tal como lo conocemos), no menor es el choque por lo que hace al inicio del filosofar. Según Fichte, este comienzo tiene lugar súbitamente, casi mediante una metánoia en la que el hombre experimenta una transformación completa. Tal es el sentido de la Tathandlung o, en la Zweite Einleitung, del "Yo como intuición intelectual» (I, 515). Y de nuevo en este caso, salvando la terminología, encontraremos una sorprendente cercanía con las concepciones del último Kant. Dice en efecto Fichte que, en este caso, el Yo no ha llegado todavía a la individualidad, sumido como ésta en la universalidad de la razón. Adviértase por demás la violenta formulación: el Yo no tiene una intuición, sino que él es la intuición de lo Absoluto en él: de lo infinito en su propia finitud, anonadada por así decir al recibir en él al Yo absoluto, que sin embargo debe llegar a ser él mismo a través de la acción humana. Pues bien, de ese "Yo-Intuición" "yace la forma del Yo", sin relación ninguna con lo "material del mismo": algo que él ha de ganar mediante su pensar activo o su acción pensante (cf. I, 516). Por su parte, Kant repetirá incesantemente desde 1799 que el comienzo de la filosofía se da con una autoposición del Yo que es puramente formal, un vehículo lógico, como ya en el Ich denke de la primera Critica ${ }^{48}$. Expresamente señalaba Kant en 1787 que: "Esta representación es un pensar, no un intuir.» (B 157). Por lo demás, esa unidad analítica de la apercepción estaba subordinada, como es sabido, a la unidad sintética. Pues bien, ambas premisas son negadas en O.p., con lo que parece darse una efectiva proximidad a Fichte. Para empezar: «El primer acto intelectual es la conciencia de sí mismo, un acto (Act) del pensar a priori» (XXII, 477). Y tal acto viene explícitamente descrito como una autointuición: «El primero es aquél mediante el cual el sujeto se pone a sí mismo primordialmente en la intuición (cognitio primaria).» (XXII, 20; cf. XXII, 442). La inversión res-

${ }^{48} \mathrm{Cf}$. el famoso inicio de " 16 de $K r V-B$ : «El: Yo pienso ha de poder acompañar a todas mis representaciones." (B 131). En la idea de können va implícito desde luego que se trata de una posibilidad lógica, aunque esa posibilidad sea necesaria. A esa vacua representación, el foco de las categorías, la apercepción pura, va necesariamente referido "todo lo múltiple de la intuición." (ib.). 
pecto a la primacía de la unidad analítica sobre la sintética no debiera ya sorprendernos. Se trata de una prioridad lógica, pensada en favor de la posibilidad de recepción de las percepciones. El sujeto se afecta a sí mismo (Selbstaffektion) en vista de lo múltiple dado (es pues, obviamente, una primacía lógica, no cronológica o psicológica). Ahora bien, con ese acto se pone el Sujeto a sí mismo como Objeto de sí. Esa posición de un Objeto en general corresponde -y de este modo contesta Kant a la vieja objeción de Jacobi- a la cosa en si ${ }^{49}$. ¡La cosa en sí no es sino el Yo objetivado, puesto por así "hacia fuera", del mismo modo que el éter era el espacio-tiempo "fisicalizado"! Kant no habría podido llegar, creo, a esta sorprendente conclusión - bien distinta a la de Fichte- sin el estudio previo del extraño estatuto trascendental del éter... y sin la influencia ¡de Beck!: "La conciencia de mí mismo en la fórmula "yo soy" es idéntica a la de la proposición: «soy para mí mismo un objeto, y además de intuición interna (dabile) y del pensar la determinación de aquello que yo me atribuyo ( $m i r$ beylege) (cogitabile).» (XXII, 449). Esa determinación pensada en general es la cosa en sí. Por sorprendente que esta idea pueda parecer, hunde sus raíces ya en la Crítica: la «síntesis trascendental a partir de meros conceptos", se decía ya entonces, "no concierne nunca sino a una cosa en general." $\mathrm{Y}$ pocas líneas después se decía que «en los problemas matemáticos" no venía considerada en absoluto la existencia, sino "las propiedades de los objetos en sí mismos» (A 719/B 747). La cosa en general vendrá identificada en O.p. con el producto de la autoposición del Yo, o sea: con un Objeto trascendental (la $\mathrm{x}$ de la primera edición de la Crítica: cf. A 109), mientras que el fundamento de esos uobjetos en sí» tratados por las matemáticas será el fenómeno del fenómeno: un constructo pensable a partir del sistema de las fuerzas motrices y de la diádica leibniziana. Por otra parte, esta noción de la cosa en sí como Objeto, o sea, como el propio Sujeto puesto por sí mismo, estaba ya implícitamente anunciada en un hermético pasaje de los "Paralogismos", en el que se hablaba de la "vacía representación: Yo, de la cual ni siquiera cabe decir que sea un concepto, sino una mera conciencia que acompaña a todo concepto. Por este Yo, o El, o Ello (la Cosa) que piensa no viene representado sino un sujeto trascendental de los pensa-

${ }^{49}$ Recordemos la famosa objeción, presente en la ya citada Beylage de David Hume oder der Glauben: "He de confesar que ese tenor (a saber: que la cosa en sí sea causa de los fenómenos, F.D.) ha obstaculizado no poco mi estudio de la filosofía kantiana, de modo que me vi precisado a empezar año tras ańo la Crítica de la razón pura una y otra vez, desde el principio, porque incesantemente me extraviaba el hecho de que yo, sin aquel presupuesto, no podía entrar en el sistema, y con ese presupuesto no podía permanecer en él.» (p. 222s.). 
mientos = x.m (A 346/B 404; subr. mío). Como cabe apreciar, acicateado por sus "amigos hipercríticos", Kant no hace ahora sino explicitar audazmente esos supuestos. Hacia "arriba», diríamos, la cosa en sí no es sino el propio sujeto "expuesto" analíticamente, explayándose, diriamos, como un foco que se expande en el sistema categorial y de predicables. Hacia "abajo", en cambio, acoge sintéticamente al Objeto posible del fenómeno, al abrirse el sujeto intuititivamente como espacio y tiempo (autoposición sintética). Esta difícil doctrina, sin embargo coherente con los presupuestos críticos, viene afortunadamente bien descrita en un pasaje clave de O.p., que merece ser meditado en su integridad: "La cosa en sí (ens per se) no es otro Objeto, sino otra relación (respectus) de la representación el mismo Objeto, a fin de pensar a éste no analíticamente, sino sintéticamente como compendio (complexus) de representaciones intuitivas en cuanto fenómenos, es decir, de representaciones tales que contengan un fundamento, meramente subjetivo, de determinación de representaciones en la unidad de la intuición. Es un ens rationis = X, de la posición del propio Yo (seiner Selbst) según el Principio de identidad, en el cual el sujeto es pensado como afectándose a sí mismo, y por tanto sólo como fenómeno, según la forma.» (XXII, 26s.). Las últimas palabras de esta densa cita muestran por lo demás palmariamente lo cercano que se halla aquí Kant del "Yo-Intuición" fichteano. Partiendo de la autoposición, el Yo inicial, esa vacua y lógica representación, se afecta a sí mismo, tornándose en Objeto en el fenómeno, es decir, reconoce su finitud.

Dicho con todo rigor: la Cosa en sí no es ni un objeto dado (per impossibile) a los sentidos ni un Objeto ajeno al campo trascendental (lo cual sería aún más impensable, como vio ya Jacobi): "sino sólo el Principio del conocimiento sintético a priori de lo múltiple de la intuición sensible en general y de su ley de coordinación. (...) no es ningún ser existente, sino $=\mathrm{X}$ : simplemente un Principio." (XXII, 33). A parte ante, proviene de la posición del sujeto como determinación omnímoda: pura unidad formal en favor de la experiencia. $A$ parte post, la "cosa" se encapsula por así decir en el sujeto finito, en búsqueda incesante de nuevas determinaciones, hasta — si se permite la gráfica expresión- "hincharse de mundo". El sujeto no está constituido en esta tensión, sino que la constituye: él mismo es la tensión entre la universalidad vacía inicial y la plena articulación "material» del final. Bien.) No dice acaso lo mismo Fichte? No. No lo dice. Fichte cuenta una historia: la historia pragmática de la autoconciencia. Kant expone un hiato insalvable: el hombre será siempre, irreductiblemente, a la vez "habitado" por la Tensión y "habitante» del mundo. Nunca, qua sujeto finito ( $y$ por ende, Objeto en el fenómeno) podrá alzarse a 
ese "Yo-Idea" que Fichte entrevé para el final de los tiempos, cuando la Doctrina de la Ciencia se haya tornado prácticamente en Ciencia. Kant se mueve únicamente dentro de la posibilidad de la experiencia, no dentro de la realización tecnopráctica o ética de la misma. Es más: en los últimos fragmentos de O.p. ha efectuado un audaz "paso atrás", para preguntarse por la posibilidad de la posibilidad de esa experiencia global, adelantando la autoposición como condición previa de la autoafección y la autointuición ${ }^{50}$. Pero se niega a dar un "paso adelante». Nunca el impulso hacia la forma "engullirá" el impulso hacia lo material, hasta que todo sea en todo. Kant no es ningún redentor del género humano: "En qué medida puedan convivir en el mismo ser dos tendencias tan opuestas es un problema que puede, ciertamete, poner en apuros al metafísico, pero no al filósofo trasscendental. Éste no se precia, en modo alguno, de explicar la posibilidad de las cosas, sino que se conforma con establecer sólidamente los conocimientos a partir de los cuales llegue a ser concebida la posibilidad de la posibilidad de la experiencia." (XXI, 76). Este decisivo pasaje, escrito en 1802, es una copia literal de un fragmento de la Carta XIX de Über die ästhetische Erziehung des Menschen, de Schiller ${ }^{51}$. Con sólo una adición, pero decisiva: la duplicación de la "posibilidad", lo cual significa, nada menos, la prioridad de la lógica formal (regida por el Principio de Identidad, que en el O.p. aparece constantemente $)^{52}$ respecto de la mismísima lógica trascendental: la primacía del análisis sobre la síntesis, en una palabra. Con una importantísima precisión: esa prioridad lógica viene secretamente orientada y guiada por la necesidad de salvar

${ }^{50} \mathrm{XXII}, 32:$ «El Objeto $=\mathrm{X}$ (lo dabile) presupone la unidad de composición de lo múltiple según la forma (cogitabile), como un Principo de la forma, a saber: del objeto en la intuición, la cual está a priori a la base; la cosa en si es ens rationis.» Como ens rationis había considerado justamente Kant en la ?tabla de la nada? al objeto de un concepto al que no le corresponde intuición alguna. Y los ejemplos aducidos son justamente los reivindicados ahora en O.p. (la cosa en sí como respectus cogitabile, y el éter): el noumenon (ens rationis) «o ciertas nuevas fuerzas básicas, pensadas ciertamente sin contrradicción, pero también sin ejemplos de la experiencia.» ( $\mathrm{KrV}$ A 291/B 346s.). Pero si esos "objetos» no están ejemplificados en la experiencia, bien pueden servir para pensarla, para establecerla problemáticamente como una omnimoda determinario. Y por lo demás, la "cosa en sim, ahora reconsiderada, sí brota por así decir de una intuición: la autointuición de "Yo soy", en favor de la experiencia. En una palabra: Kant busca ahora la posibilidad (pensable) de la posibilidad (dable) de una y la misma experiencia.

${ }^{51}$ Vid. p.e. la ed. Reclam. Stuttgart 1977, p. 77 s.

${ }^{52}$ Según una ordenación temática y cronológica (de la regla de identidad como condición de pensabilidad del érer hasta lo cogitabile para admitir la presencia de Dios en nosotros como Idea moral), los pasajes decisivos en que se habla del Principio de Identidad son: XXII 551, 487, 517 s. $523,543,434,443,447,11,19,26,28,33,40,409,420,421,68,84,85,93,95,98$, $106,113,50,53,61,129 ; \mathrm{XXI}, 92$. 
los fenómenos (incluyendo desde luego en ellos, en primer lugar, al sujeto empírico, como cuerpo vivo, Leib: centro del universo en cuanto habitante espacio temporal del mundo). Si lo cogitabile es siempre (para el análisis del filósofo) anterior a lo dabile, ello se debe a que, en el mundo real, nos vemos precisados a reconocer la imposición de lo dado, y hemos de prepararnos para acogerlo, a fin de modificarlo ulteriormente y prever su aparición, siempre desde un respecto formal. Cuál sea el origen de lo "dado" stricto sensu, ignoramus et ignorabimus. El Yo no pone en Kant al No-Yo (término que en vano buscaríamos en sus textos). Es siempre demasiado tarde para avistar lo múltiple en cuanto tal. Lo múltiple está ya de siempre en nosotros. Pero no es de nosotros: ni al inicio, ni al final. Porque la filosofia trascendental kantiana no sabe nada de historias. Kant no pasa jamás la Grenzlinie, sino que opera en el interior de las representaciones.

Como un acróbata arriesgado, Kant se pasea al borde del precipicio del Absoluto, pero nunca cae en él. Utiliza expresiones que "suenan" a Fichte, para inmediatamente dar un quiebro y desmentirlas, in actu exercito. Incluso se permitirá alentar, entre la condescendencia y la ironía, a su "amigo hipercrítico", con ocasión del acuse de recibo (único que hiciera, por lo demás) de neuen Stücke por parte de Fichte (con seguridad, las dos Einleitungen). En esa carta, probablemente de diciembre de 1797 (XII, 221s.), ironiza Kant sobre las «sutilezas de la especulación teórica» y anima al "discípulo" a que continúe por la senda de la Popularität (algo que Fichte debió tomar como una ofensa: y seguramente era ésa la intención de Kant) y se aleje de la uespinosa senda de la escolástica" (en clara alusión a la Grundlage, que él conocía sólo por la recensión de A.L.Z.). Fichte contesta rápidamente (el 1 de enero de 1798): "No pienso en absoluto abandonar la escolástica. La impulso con gusto y facilidad, y ella fortalece y acrecienta mi fuerza.» (XII, 231). Poco después, la ruptura definitiva. El resto no es historia, sino la carne viva, felizmente dolorida, de la filosofía.

Estas tormentosas relaciones dejarían sin embargo su fruto. A través de la posible lectura de la Zweite Einleitung, de recensiones sobre la obra fichteana, y con seguridad de las conversaciones con Johann Schultz y de los consejos de éste, así como, last but not least, de la necesidad interna de revisar los propios fundamentos críticos, Kant emprendió un camino de retorno que, para nosotros, hoy, resulta absolutamente crucial para empezar a entender esa espléndida encrucijada entre el criticismo y el idealismo, junto al pujante regreso del escepticismo nehumeano, del spinozismo y de un neoleibnizianismo por parte, malgré lui, de Jacobi, pero también de Herder y de Heydenreich. Y, sobre todo, de Schelling 
(en el trasfondo, una sombra que va alzándose, gigantesca: la figura de Hegel). Demasiados factores como para etiquetarlos, sin más, de «idealismo». Ésta es una madeja que tardará mucho la investigación en desenredar.

Tomemos al menos, para concluir, uno de los últimos hilos de ese enmarañado ovillo. Si Fichte influyó en Kant como reactivo y aun revulsivo para que éste tomara conciencia de las últimas consecuencias de su inacabado sistema, ¿cabría decir lo mismo de Schelling? En principio, todo parece inclinar a una respuesta negativa. Salvo por los escritos de Filosofia de la Naturaleza (en los que Kant parece no haber reparado en demasía $)^{53}$, durante los años noventa era Schelling considerado como un mero discípulo y hasta divulgador de Fichte. Y si éste fue despachado con desprecio (al menos, exteriormente) por parte de Kant, ¿cómo iba a fijarse en su discípulo? Sin embargo, en fecha relativamente reciente (1991) ha reivindicado Burkhard Tuschling en un importante ensayo ${ }^{54}$ la influencia de Schelling en el último Kant ${ }^{55}$. Y aunque sus conclusiones me parecen francamente exageradas, tanto por lo que hace a ese influjo como respecto a un retorno del idealismo trascendental a las "convicciones fundamentales del racionalismo metafísico" (p. 132), el vigor de sus afirmaciones exige desde luego una revisión de las relaciones entre el último Kant y el primer Schelling, si no documentables (cosa que el propio Tuschling, naturalmente, acepta en p. 123), sí al menos dignas de estudio por la cosa misma del pensar.

Kant cita a Schelling sólo en dos ocasiones, sin la menor indicación de sus doctrinas. El primer pasaje, sin duda misterioso, reza así: «Sistema del Idealismo trasc. por Schelling, Spinoza, Lichtenberg, al modo de 3 dimensiones: el presente, el pasado y el futuro.» (XXI 87, 29-31). La cita es muy tardía (de 1802). Está flanqueada ${ }^{56}$ por una alusión al Dios de Spinoza (a saber: que nos repre-

${ }^{53}$ En todo caso, el primer escrito en este sentido es Ideen, de 1797, cuando Kant empezaba a sumirse en sus elucubraciones sobre el calórico y el éter (una temática que no entra en las consideraciones de Schelling). Von der Weltseele, de 1798, se preocupa de las relaciones entre la gravedad (Schwere) y la luz (Licht): dos principios antitéticos que en nada podían ayudar a Kant para fundamentar su única materia trascendental básica: el éter. Es verdad que en XXII 62, 78, 97 , 504 y 507 alude Kant a un "alma del mundo»: pero sólo para rechazar esa hipótesis (salvo en el caso - ambiguo- de XXII 62), y reforzar en cambio su concepción de la tercera Crítica: «se trata aquí solamente de una causa eficiente por analogía con una inteligencian (XXII, 507).

${ }^{54}$ Citado supra, en nota 37.

${ }^{55}$ Negada en cambio radicalmente por Adickes (op. cit., p. 33s., 756, n. 2, 840, 850), como el propio Tuschling reconoce en nota 59, p. 139 de su ensayo.

${ }^{56}$ Aunque esto no es muy significativo en el legajo I, donde Kant anota una detrás de otra las temáticas más dispares. 
sentamos a Dios en la intuición pura), seguida por una Nota Bene, en la cual contrapone Kant esa supuesta teoría (mezcolanza de Lichtenberg con la intuición intelectual schellingiana del Absoluto) a la suya propia, esto es: que el espacio es Objeto (aunque, añadimos nosotros, indirecto) de la razón pura, pero no una idea. Y tras el pasaje citado viene una definición ${ }^{57}$ de la Filosofía Trascendental como «lo formal del conocimiento sintético a priori a partir de conceptos", a fin de establecer globalmente la idea de los objetos. Nada nuevo, pues. Por la ubicación entre esos dos breves textos, todo parece indicar que al menos conla alusión a Schelling, Spinoza y Lichtenberg pretende Kant desembarazarse del rótulo de "Sistema del Idealismo trascendental» (justamente el título de la gran obra de Schelling, de 1800), dejándoselo a los presuntos «idealistas», para atenerse al genuino de: "Filosofía trascendental». Justamente en el pasaje siguiente (XXI, 88) se pregunta Kant: «Y si el sistema idealista (que yo mismo sea el mundo) fuera el único pensable por nosotros? La ciencia nada perdería en ese caso." Ahora bien, lo que Kant hace aquí es plantearse - retóricamente- la pregunta:)y si Lichtenberg tuviera después de todo razón? Pues Kant no ha dicho jamás, que yo sepa, que el yo sea el mundo (como tampoco que yo, o el "Yo», sea Dios). Lichtenberg, en cambio, sí: «En general nunca se pararán mientes (bedenken) de manera suficiente en que nosotros no hacemos sino observarnos a nosotros mismos cuando observamos la naturaleza y sobre todo nuestras ordenaciones (Ordnungen).» (II, 36). Y la respuesta kantiana, no menos retórica, es: no pasaría nada por lo que hace a la ciencia. En efecto, Lichtenberg fue un gran científico (al que las partes protofísicas de O.p. deben mucho) y sin embargo un representante extremo del idealismo subjetivo. También lo será, andando el tiempo, el gran Arthur Stanley Eddington, que aduce - seguramente sans le savoir - un ejemplo parecido al de Lichtenberg: la huella de un pie en la playa del mar de lo desconocido (en Lichtenberg, más prosaico, que veamos en la arena rostros, paisajes, etc.). En este punto, al menos, Schelling está completamente fuera de la consideración de Kant.

Por lo demás, es comprensible que el anciano otorgue la dimensión del "presente" a la obra de Schelling, que acababa de aparecer ${ }^{58}$. Prueba de ello es la

57 Una más, entre las aproximadamente ciento cincuenta que da en este período final.

58 Por lo demás, que adjudique a Spinoza el "pasado» es comprensible (aunque difícilmente nadie vería hoy en él a un representante o precursor del idealismo trascendental). Más extraño es que Lichtenberg represente el "futuro". En todo caso, y puesto que Kant no estaba de acuerdo con su egotsmo trascendental (como Tuschling reconoce en p. 141, n. 68), ello abona aún más la tesis de que Kant rechazaba para su propia (deseado) doctrina — al menos en este contexto- el título: «Sistema del Idealismo trascendental». 
segunda cita: «System des transsc: Idealism von Schelling. vide Litteratur//Zeitung, Erlangen No. 82, 83.» (XXI 97, 25), antecedida y seguida igualmente por sendos intentos de definición de la Filosoffa trascendental. Eso es todo. Que de ahí pueda extraer Tuschling la tesis de que Kant «nombra como autores y representantes de la posición que él mismo mantienem a los tres filósofos citados (p. 115) es, como poco, sorprendente. Y que conociendo a Kant a través de su epistolario pretendiera éste, en vida y en plena actividad, reconocer a Schelling como "legítimo heredero del idealismo trascendental» (ib.), me deja estupefacto. Kant exigía, como sabemos por la Declaración contra Fichte, que su sistema fuera interpretado al pie de la letra, y el único a quien reconocía autoridad en esa materia era —algo tan lógico como triste- Johann Schultz, tras la «traición» de Beck.

Ciertamente, cabe aceptar que las noticias que Kant pudiera haber tenido de la obra schellingiana quizá le habrían hecho sentir más aprecio por ella que por la de Fichte: al fin, tanto Kant como Schelling están ocupados en la misma época en el enlace de la lógica o, si se quiere, del idealismo trascendental y la física (aunque en Kant nunca sea ésta "especulativa", y menos pretenda él competir con la física de los científicos). Ambos pensadores son dinamicistas y, diríamos, energetistas. Ambos buscan deducir la totalidad de la experiencia a partir de una actividad originaria, por más que en Kant sea ésta establecida sólo de modo problemático y en favor de la experiencia, y en modo alguno desde un Absoluto omniabarcador, captable en una intuición intelectual. Que Kant utilice alguna vez la expresión Selbstanschauung podría indicar alguna influencia de Schelling, sobre todo en un pasaje en el que rompe la gradación normal (primero: acto de apercepción analítica; segundo: autoafección en favor de los fenómenos) para señalar que el "hacerse a sí mismo objeto de los sentidos» es «al mismo tiempo que sintética, analítica" (XXII, 442). Con mucha buena voluntad y algo de imaginación cabría sentir aquí un lejano eco de la schellingiana autointuición del Absoluto a la vez en el sujeto consciente y en la naturaleza. Pero decir, como hace Tuschling (p. 124), que Kant toma el término Selbstanschauung de Schelling es desde luego un hysteron proteron. Kant utiliza ese término en la segunda edición de la Critica en tres ocasiones: 1) para hablar de la Selbstanschauung des Gemüts, tal como éste afecta a nuestros sentidos (B 69), o sea: en el contexto de la autoafección, doctrina como sabemos ampliada y profundizada en O.p., pero no cambiada en favor del idealismo absoluro; 2) para señalar que el modo en que pongo (setze) en mí lo múltiple no es algo dado, sino que para ello es necesaria la Selbstanschauung, que tiene como fundamento la intuición pura del tiempo (B 157, A.); y 3) al final de los «Paralogismos» (B 432), para evitar que se apli- 
que esa doctrina a las elucubraciones metafísicas de la psicología racional, recordando al respecto que el "Yo pienso", si entendido como "ich existire denkend", implica no sólo espontaneidad del pensar, sino también receptividad de la intuición. Es decir, el pensamiento de mí mismo se aplica a la intuición empírica de ese mismo sujeto.» (B 429s.), lo cual nos lleva obviamente a la doble autoposición del sujeto en O.p.: como Cosa en general, y como Objeto en el fenómeno. Todo lo cual indica que cuando el último Kant usa el término Selbstanschauung lo hace para reformular, de un modo ciertamente más «subjetivista», doctrinas de la Crítica. Esa obra es la que entonces lee y relee una y otra vez Kant. Con ella hay que confrontar los fragmentos póstumos sobre la intuición de sí mismo, y no con una recensión de la revista de Erlangen.

Pero lo que a mi ver es de todo punto desatinado es la conclusión que de todas las presuntas influencias de Schelling sobre el último Kant extrae Tuschling, a saber: que "el sujeto es, él mismo, Dios» (p. 130). Mirabile auditu! Pues lejos de ser en Kant el «medio de enlace» (Verbindungsmittel; esto es, el Hombre como copula) nada menos que el: «concebir y querer originariamente activo y absoluto" (ib.), el actus primero de la autoposición kantiana es, como hemos probado suficientemente, puramente analítico y conduce a una fenomenización (de primer grado, ciertamente: como protofenómeno del fenómeno) del sujeto mismo. Ciertamente: Est Deus in nobis (XXII, 130). Pero esto lo sabemos ya desde Pablo, Agustín y Lutero, sin que a Kant se le haya ocurrido inferir de ello que "Yo" soy Dios. A lo más que llega el pensador, en formulación desde luego atrevida, es a decir que: «Es necesario progresar de la razón técnico -práctica a la moral - práctica, y del sujeto como ser natural al subjeto como persona, esto es, como puro ser del entendimiento (Verstandeswesen) Dios." (XXII 49, 17-20). Tuschling reproduce la cita, mutilándola de este modo: «dass das 'Subjekt als Person, d.i. als reine[s] Verstandeswesen, Gott' ist.» (p. 120). Y agrega que esto es incompatible con los postulados de la segunda Crítica.

Ahora bien, que Dios sea el sujeto ideal de la proposición "Dios-Mundo", cuya cópula es el hombre (justamente, como ciudadano de dos mundos, y en absoluto como el Absoluto), es algo que ya hemos analizado detenidamente. Pero de ahí no se sigue que Dios sea el sujeto de la autoposición Ich bin, y menos que se identifique con el «Sujeto-Yo». Además, el propio Kant tilda a esa "Persona» de Verstandeswesen, o sea, en buena terminología clásica, de ens rationis: un punto confirmado por numerosos pasajes de O.p. Véase por ejemplo XXII 123s.: "Ens summum, summa intelligentia, summum bonum: es el ens ratio- 
nis pensado o más bien inventado (gedichtet) como ser natural, una sustancia omnicomprehensiva e inescrutable; pero como ser moral [es] un Principio de la [razón] práct[ica] "59. ¡Hacer de una ficción en favor del cumplimiento del deber (visto así como un mandato emanado de una Persona) un «concebir y querer originariamente activo y absoluto" parece demasiado! Es más, la cita que el propio Tuschling aporta como justificación de su aserto (de p. 130) más bien lo desmiente de un modo radical. Dice Kant, en efecto: "La filosofía trascendental no se ocupa de algo que haya de ser admitido como existente, sino meramente (bloss) del espíritu del hombre, que [es] el propio sujeto pensante de éste." (XXI 78, 16-19).

Sólo en este último sentido (el espíritu como sujeto pensante del hombre) cabe entender la siguiente y audaz afirmación de Kant (que, mutilada y fuera de contexto, podría hacer ciertamente estragos en la Kant-Forschung): «El espíritu del hombre es el Dios de Spinoza." Pero Kant sigue escribiendo: "(lo que concierne a lo formal de todos los objetos sensibles), y el idealismo trascendental es realismo en sentido absoluto." (XXI, 99). Ahora bien, dadas todas las citas ya acumuladas, cabe interpretar este pasaje dentro de las estrictas coordenadas críticas: 1) Kant entiende aquí "Spinoza" en el sentido de Lichtenberg; 2) sin que acepte desde luego la doctrina del último, sobre todo en un respecto capital, a saber: no es lo mismo conocer un objeto que pensarlo como un modus del Actus de espontaneidad (cognitio primaria): la anticipación es sólo formal, como explícitamente se señala en ese pasaje; 3 ) lo que Kant quiere decir aquí, palmariamente, es: una vez bien consolidado el giro copernicano, no tiene ya sentido utilizar el conceptus fanaticus de Spinoza, cuyo Dios es una sustancia ${ }^{60}$; y 4) seguimos situados en la línea de la "Refutación del idealismo", con una importante matización: el idealista trascendental no es ya, meramente, un realista empírico (cf. $\mathrm{KrV}, \mathrm{A} 373$ ) sino un realista "en sentido absoluto", por la sencilla razón de que es impensable - y ya, innecesario- admitir una "realidad" existente más

59 Cf. XXII, 126: «Un Ens tal, empero, puede ser constituido como Principio solamente en cuanto hipotético: no como dado, sino sólo como pensado (ente de razón [Gedankending], ens rationis), y esto únicamente en favor del reconocimiento de nuestros deberes como mandatos divinos." La analogía con el éter es palmaria: aceptamos problemáticamente esa "materia" de base en favor de la experiencia de igual modo que aceptamos un Principio «inmaterial" en favor del cumplimiento del deber. En XXII 127 llama Kant a Dios: Vernunftwesen, lo que le acercaría al menos terminológicamente a la "Idea-Yo» con la que Fichte cierra su sistema.

${ }^{60} \mathrm{XXI}, 19$ : «El concepto de Spinoza de Dios y del hombre - según el cual intuye el filósofo todas las cosas en Dios- es fanático (conceptus fanaticus)". 
allá de lo fenoménicamente presente, gracias a la nueva doctrina de la "cosa en sín: ésta no es, como ya hemos visto, sino el espacio lógico —diríamos-, o sea: el respecto activo, autoproducido por el sujeto, en el que los objetos de la experiencia pueden acomodarse, no sólo a la intuición pura, sino también a las formas categoriales. La ampliación de la doctrina crítica no es una modificación de ésta, y menos un regreso a las posiciones de la metafísica racionalista ()acaso el propio Schelling volvió a éstas?), sino una consolidación de la misma.

Dicho esto, bien puede concederse que en este y otros pasajes haya cierta influencia de Schelling (que en todo caso serviría, como estamos viendo, para hacer reflexionar a Kant sobre la solidez de sus propios presupuestos, y no para abrazar las nuevas corrientes). En efecto, es bien posible que Kant tuviera noticia de la Allgemeine Uebersicht der neuesten philosophischen Literatur ${ }^{61}$, que apareció anónimamente en el Philosophisches Journal de Fichte y Niethammer. En este tratado se dicen cosas importantes justamente sobre el concepto de espíritu (Geist). Kant podría haber aceptado desde luego, al respecto, la siguiente frase: "Llamo espiritu a aquello que es sólo su propio Objeto». (I/1, 246). E incluso admitiría (con reservas por lo que hace al carácter "absoluto" del sujeto) que tal espíritu no es: «originariamente Objeto, sino sujeto absoluto, para el cual todo (incluso él mismo) es Objeto.» $(\mathrm{I} / 1,247)$. Con una importante restricción, empero: que tal «sujeto" es según Kant meramente pensado en favor de la experiencia, no desde luego el sustituto de la cosa en sí, y menos un: «eterno devenin (ib.). ¿Cómo va a convertirse en un «eterno devenir» un actus meramente cogitabile? Por lo que hace a la cosa en sí, también aceptaría Kant, con Schelling, que ésta no es sino el abstractum de un Objeto en general, es decir: cuando se hace abstracción de todas las propiedades posibles de un objeto cualquiera, quedando sólo: «un Algo indeterminado y lógicom $(I / 1,234)$. ¡Pero, para Kant, esto no significa en absoluto que, en virtud de su carácter abstracto, haya de ser desechada esta noción! Al contrario, ahora es cuando la cosa en sí tiene de verdad una función importante. Atiéndase a esta triple gradación: «Lo determinabile es la cosa en sí; lo dado por el entendimiento, [es lo] puesto sintéticamente a priori según la forma (dabile); lo múltiple de la intuición, lo assignabile.» (XXII, 418).

61 En la reedición de 1809 , denominados muy significativa y provocativamente (contra Fichte, claro): Abhandlungen zur Erläuterung des Idealismus der Wissenschaftslehre (1796/97), S.W. $\mathrm{I} / 1,343-452$. 
Justamente por ser algo «indeterminado y lógico», la cosa en sí cumple a la perfección el cometido asignado a la materia lógica de la posibilidad, en cuanto concepto de reflexión, según la doctrina de la "Anfibología" de la primera Crítica. Allí, en efecto, venía considerada la materia (siempre en el respecto lógico, como cuando se habla de la "materia" del silogismo) como das Bestimmbare überhaupt (A 266/B 322), lo cual corresponde exactamente al primer punto de la gradación citada. La forma, por su parte, es «la determinación de éste» (de lo determinable), y siempre abstrayendo en ambos casos de lo dado y del modo específico de determinación, lo cual concuerda con el segundo punto del texto citado (Setzung de lo dado por el entendimiento, o sea: de las determinaciones), así como con la interpretación schellingiana de la cosa en sí como un abstractum. De esta manera logra Kant, al menos por lo que respecta a lo dabile, salir del impasse de su típico dualismo, concisa y certeramente criticado por Schelling: "La forma de nuestro conocimiento - según Kant, se entiende- viene de nosotros mismos, la materia del mismo nos viene dada de fuera." (I/1, 244). En el último Kant, en cambio, tanto la materia como la forma del conocimiento en cuanto que conocimiento (o sea, en cuanto espontaneidad del conocer) vienen del doble acto de autoposición (analítico) y autoafección (sintético), mientras que tanto la materia como la forma, la configuración de lo conocido en cuanto tal: de lo empírico, siguen siendo dados.) No es ésta acaso la esencia de todo experimento científico? Construimos teorías y aparatos de medida para corresponder en lo posible a lo imprevisible e impenetrable dado. De la misma manera, podemos adelantar la tópica de los deberes posibles, con respecto a nuestro obrar. Pero la ocasión de este obrar no está en poder del hombre. En suma, constructivismo no es idealismo: ni subjetivo, ni absoluto. Hay un resto inasimilable. Por fortuna. Porque en ese resto está todo lo que de veras importa. Esa es una lección que aprenderá Schelling mucho más tarde, cuando reconozca que la filosofía negativa sólo alcanza a la esencia de las cosas y que la razón se estrella, estupefacta, frente al factum de la existencia.

Al fondo, desde su retiro de Königsberg, el viejo Kant rejuvenece en el pensamiento, gracias a las audacias de sus "amigos hipercríticos». Y espera, mientras su cerebro va siendo oprimido por una progresiva pachymeningitis. El sabe que: "Sophus (el Sabio) es meramente un ideal, y es solamente único", y que en cambio: "Philosophus Homo est.» (XXI, 157). No importa. El sabe también que como hombre va a morir, pero que las palabras del filósofo no morirán. En su terror senil siente acechada su casa por manadas de gatos, escapados de la mortandad que de ellos se hizo en Erlangen, y que han atravesado Alemania hasta 
Königsberg con el solo objeto dẹ contagiarle eléctricamente una misteriosa enfermedad (XXII, 90) y le dan miedo los ojos petrificadores del basilisco; pero se consuela comiendo salchichas de Göttingen regaladas por Nicolovius (XXI, 71) y regalándose con mazapán (XXI, 5) y una botella de buen vino cacavello (Cacabelos, en el Bierzo español) (XXII, 89). El sabe esperar, incluso al ingresar en la noche láctea de su "Coma vigil", en su "Insomnio continuo" (XXI 3). En una conversación con Friedrich August Stägemann del año 1797, parece que dijo: "Con mis escritos he llegado un siglo antes de tiempo; sólo después de cien años se me entenderá correctamente, y entonces mis libros tendrán valor y serán de nuevo estudiados" ${ }^{62}$. Fue demasiado pesimista, a pesar de su terca paciencia. Llevamos dos siglos y hemos pasado al tercer milenio estudiando y valorando sus libros, su probidad y su denuedo. Lo único que quizá no sepamos nunca es si lo hemos entendido correctamente.

No importa. De nosotros mismos, incluyendo las flaquezas del viejo, callemos. De re autem, quae agitur, petimus: ut homines eam non Opinionem, sed Opus esse cogitent. Aunque el Opus sea póstumo.

${ }^{62}$ Cit. en Friedrich Ueberweg, Grundriss der Geschichte der Philosophie. Völlig neubearbeitet von M. Frischeisen-Köhler und Willy Moog. Berlin 1924'2; III, 509. 